\title{
Developmental Changes in HCN Channel Modulation of Neocortical Layer 1 Interneurons
}

\author{
Andrew S. Bohannon and John J. Hablitz* \\ Department of Neurobiology, University of Alabama at Birmingham, Birmingham, AL, United States
}

Layer 1 (L1) interneurons (INs) play a key role in modulating the integration of inputs to pyramidal neurons (PNs) and controlling cortical network activity. Hyperpolarizationactivated, cyclic nucleotide-gated, non-specific cation $(\mathrm{HCN})$ channels are known to alter the intrinsic and synaptic excitability of principal components (PCs) as well as select populations of GABAergic INs. However, the developmental profile and functional role of HCN channels in diverse L1 IN populations is not completely understood. In the present study, we used electrophysiological characterization, in conjunction with unbiased hierarchical cluster analysis, to examine developmental modulation of L1 INs by HCN channels in the rat medial agranular cortex (AGm). We identified three physiologically discrete IN populations which were classified as regular spiking (RS), burst accommodating (BA) and non-accommodating (NA). A distinct developmental pattern of excitability modulation by HCN channels was observed for each group. RS and NA cells displayed distinct morphologies with modulation of EPSPs increasing in RS cells and decreasing in NA cells across development. The results indicate a possible role

OPEN ACCESS

Edited by:

Marco Martina Northwestern University, United States

Reviewed by:

Cheng-Chang Lien, National Yang-Ming University,

Taiwan

De-Lai Qiu,

Yanbian University, China

*Correspondence: John J. Hablitz jhablitz@uab.edu

Received: 18 July 2017 Accepted: 15 January 2018 Published: 30 January 2018

Citation: Bohannon AS and Hablitz JJ (2018) Developmental Changes in HCN Channel Modulation of Neocortical Layer 1 Interneurons.

Front. Cell. Neurosci. 12:20. doi: 10.3389/fncel.2018.00020 of $\mathrm{HCN}$ channels in the formation and maintenance of cortical circuits through alteration of the excitability of distinct AGm L1 INs.

Keywords: HCN channels, interneuron development, layer 1, medial agranular cortex, synaptic integration

\section{INTRODUCTION}

In mature neocortex, a small population of GABAergic cells comprises the entirety of layer 1 (L1) neurons (DeFelipe and Jones, 1988; Winer and Larue, 1989; Hestrin and Armstrong, 1996; Zhou and Hablitz, 1996b). Cajal-Retzius cells (CR) in L1 are one of the earliest identifiable cell-types in the neocortex (Bradford et al., 1978; Chun and Shatz, 1989) and are critical for proper cortical development, specifically cortical layering (Peters and Jones, 1984; Ogawa et al., 1995). CR cells exhibit a unique morphology, featuring a prominent tapering dendrite and ovoid soma, and can be identified by their expression of reelin. However, CR cells are no longer present by the end of the second post-natal week (del Río et al., 1995; Zhou and Hablitz, 1996b; Soda et al., 2003; Chowdhury et al., 2010). Although the exact mechanism behind CR cell elimination is unclear, it has been suggested that they are removed from the cortex via apoptosis (Kirischuk et al., 2014), leaving a sparse diverse population of interneurons (INs) which remains in L1 throughout maturity. We have previously shown that L1 INs display robust "sag" responses upon membrane hyperpolarization, indicative of the presence of an inwardly-rectifying hyperpolarization-activated current $\left(I_{\mathrm{h}}\right.$; Zhou and Hablitz, 1996b; $\mathrm{Wu}$ and Hablitz, 2005). However, there has been no characterization of developmental changes in these responses or the functional impact of $I_{\mathrm{h}}$ on the excitability of those cells. 
Given L1's critical role in establishing cortical lamination and circuitry, the functional impact of hyperpolarization-activated, cyclic nucleotide-gated, non-specific cation $(\mathrm{HCN})$ channels on L1 INs during development is potentially important. Despite the absence of labeling with cell markers typically used to classify GABAergic neurons in other cortical layers (Kawaguchi and Kubota, 1997; Xu et al., 2010; Pfeffer et al., 2013), L1 INs have been shown to consist of distinct subclasses based on anatomical and electrophysiological parameters (Jiang et al., 2013; Ma et al., 2014; Lee et al., 2015). Several studies have divided mature L1 INs into late-spiking and non-late-spiking groups for characterization (Chu et al., 2003; Cruikshank et al., 2012). However, recent studies have demonstrated morphological and physiological diversity of L1 INs which is not accurately reflected when using late-spiking as the sole distinguishing feature (Kubota et al., 2011; Jiang et al., 2013). In order to better understand the diversity of L1 IN subtypes, we have examined specific mechanisms regulating the excitability and activity of L1 INs throughout development.

Changes in the excitability of discrete cell populations can disrupt cortical network dynamics and subsequently alter normal cortical function (Cossart et al., 2001; Cobos et al., 2005; Trevelyan et al., 2006; Yizhar et al., 2011). Alterations in several voltage-dependent currents have been shown to influence the excitability of neurons. In particular, studies have characterized the role of HCN channels in influencing the excitability of cortical cell populations (Robinson and Siegelbaum, 2003; Biel et al., 2009; Albertson et al., 2011, 2013). Further implicating HCN channels in regulatory control of network activity, knockout of HCN1 (Huang et al., 2009; Santoro et al., 2010) and HCN2 (Ludwig et al., 2003) has been observed to produce a decreased seizure threshold and absence seizures, respectively. Multiple experimental epilepsy models and human epilepsy cases have reported alterations in the presence and/or function of HCN channels (Dyhrfjeld-Johnsen et al., 2009; Baruscotti et al., 2010; Reid et al., 2012; Shah et al., 2012). The cell type-specific basis for these observed changes in $\mathrm{HCN}$ channel expression/function has yet to be determined.

The medial agranular cortex (AGm) is a strip of cortex lying between the anterior cingulate and lateral agranular cortex (AGl). The AGm is most strongly differentiated from surrounding cortical areas by its cortical connectivity patterns, with AGm sending projections to primary motor cortex and sensory cortical areas (Reep et al., 1987, 1990; Gu et al., 1999; Jeong et al., 2016). Based on these connectivity patterns, the AGm is considered a homolog of the premotor and supplementary motor areas of the primate cortex (Passingham et al., 1988; Sul et al., 2011). Accordingly, activation of AGm efferent fibers incites little to no motor activity (Donoghue and Wise, 1982; Sanderson et al., 1984; Neafsey et al., 1986). Rather, AGm has been demonstrated to be critical for the selection of informed or value-based actions (Kargo et al., 2007; Ostlund et al., 2009; Erlich et al., 2011; Murakami et al., 2014; Li et al., 2015). Given that L1 INs regulate information processing in cortical circuits (Cauller, 1995; Shlosberg et al., 2006; Palmer et al., 2012a; Jiang et al., 2013), regulation of the excitability of L1 cells in AGm may be crucial for maintenance of cortical output.
Identification of mechanisms which regulate the intrinsic and synaptic excitability of L1 neurons is pivotal to understand the network dynamics underlying information processing. With multiple brain regions densely innervating principal component (PC) dendrites in L1 (Cauller, 1995; Cauller et al., 1998; Rubio-Garrido et al., 2009), GABAergic cells in this layer are uniquely positioned to integrate inputs and finely control cortical output (Petreanu et al., 2009). Intrinsic neuronal excitability (Magee, 2000) and the time course of distally evoked EPSPs are increased following HCN channel inhibition. Temporal summations of EPSPs is also enhanced (Williams and Stuart, 2000; Berger et al., 2001) which can allow somatic membrane potentials to move significantly closer to threshold (Berger et al., 2001). Identifying the role of $\mathrm{HCN}$ channels in modulating excitability and synaptic integration in L1 INs will increase our understanding of the basic mechanisms governing cortical network activity which underlies information processing. To this end, we used whole-cell electrophysiological recordings to determine the extent to which HCN channels affect the intrinsic and synaptic excitability of AGm L1 INs throughout development. We have identified physiologically discrete subsets of L1 INs with distinct developmental patterns of modulation by HCN channels.

\section{MATERIALS AND METHODS}

\section{Ethics Statement}

All experiments were performed in accordance with the National Institutes of Health Guide for the Care and Use of Laboratory Animals. Research protocols were approved by the University of Alabama at Birmingham Institutional Care and Use Committee. All available measures were taken to minimize pain or discomfort for research subjects.

\section{Slice Preparation}

Acute cortical slices containing the AGm were prepared from vesicular GABA transporter (VGAT)-Venus-A-expressing Wistar rats (Uematsu et al., 2008). Animals were anesthetized with isoflurane and decapitated. The brain was quickly removed and immediately placed in ice-cold oxygenated $\left(95 \% \mathrm{O}_{2} / 5 \%\right.$ $\mathrm{CO}_{2}, \mathrm{pH}$ 7.4) cutting solution consisting of (in $\mathrm{mM}$ ): 135 $\mathrm{N}$-Methyl-D-glucamine, $23 \mathrm{NaHCO}_{3}, 1.5 \mathrm{KH}_{2} \mathrm{PO}_{4}, 0.4$ ascorbic acid, $1.5 \mathrm{KCl}, 0.5 \mathrm{CaCl}_{2}, 3.5 \mathrm{MgCl}_{2}$ and $10 \mathrm{D}$-glucose (Tanaka et al., 2008). Coronal brain slices (300 $\mu \mathrm{m}$ thick) were made using a Microm HM 650 vibratome (Microm; Walldorf, Germany). Slices were stored in saline containing (in $\mathrm{mM}$ ) $125 \mathrm{NaCl}$, $26 \mathrm{NaHCO}_{3}, 1.25 \mathrm{NaH}_{2} \mathrm{PO}_{4}, 3.5 \mathrm{KCl}, 2.0 \mathrm{CaCl}_{2}, 2.0 \mathrm{MgCl}_{2}$ and $10 \mathrm{D}$-glucose at $37^{\circ} \mathrm{C}$ for $45 \mathrm{~min}$, then kept at room temperature for a minimum of $1 \mathrm{~h}$ until recording.

\section{Whole Cell Recording}

Individual slices were transferred to a submerged recording chamber mounted on the stage of a Zeiss Axio Examiner D1 (Carl Zeiss Inc., Thornwood, NY, USA) microscope, equipped with Dodt contrast optics, a $40 \times$-water immersion lens and infrared illumination to view neurons in the slices. The recording chamber was continuously perfused with oxygenated saline 

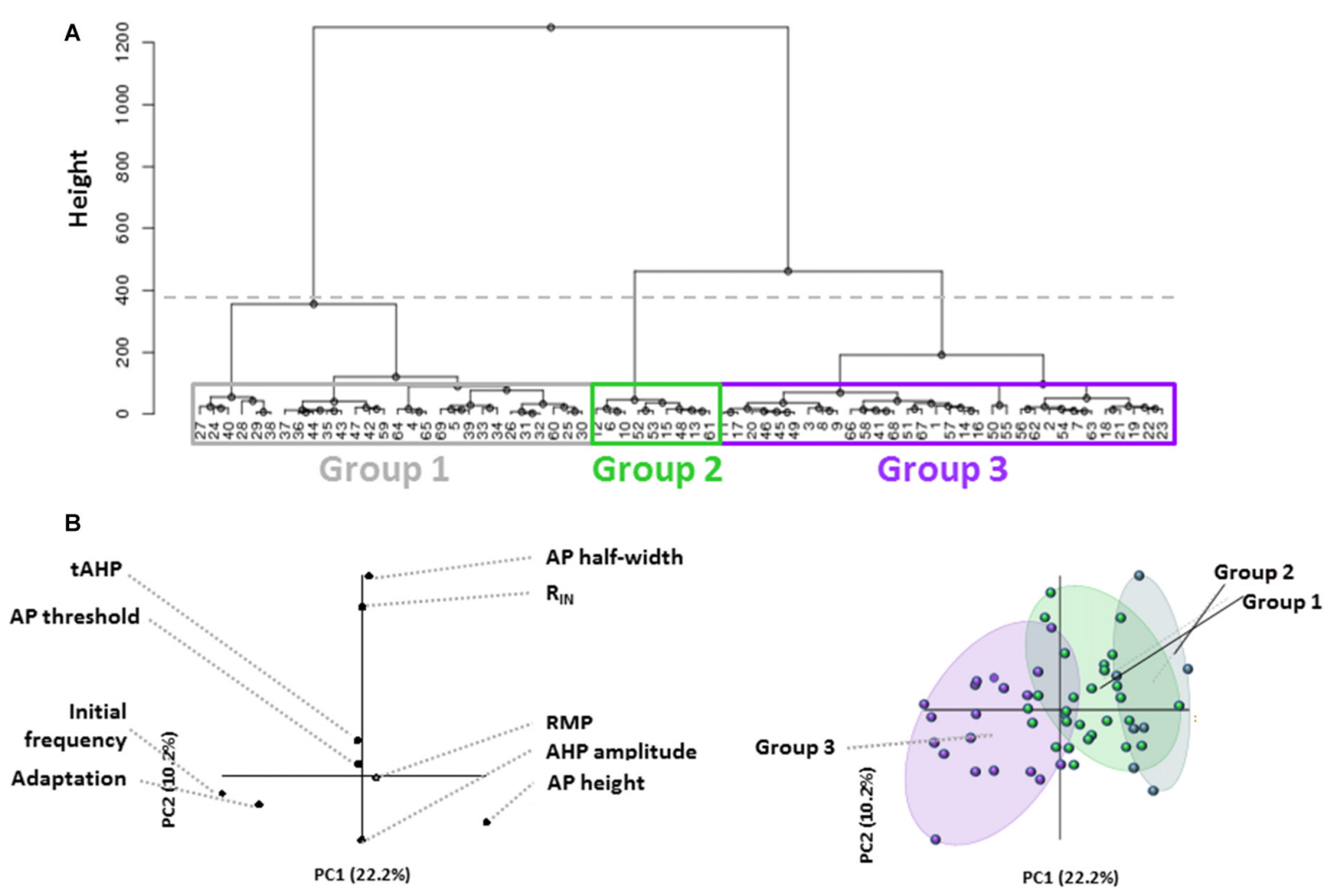

FIGURE 1 | Unbiased identification of physiological distinct layer 1 (L1) interneuron (IN) populations. (A) Dendrogram generated from hierarchical cluster analysis of electrophysiological properties of $\mathrm{L} 1$ cells. The dashed horizontal line indicates the cutoff for heterogeneous groups based on the exponential decay in the Euclidean distance between consecutive branch points. Boxes indicate the three groups identified. Colors correspond to Panel (B) right. Each terminal branch represents a recorded L1 IN, each indicated by a number. (B) Partial least squares enhanced discrimination analysis (PLS-EDA) was used to ascertain the defining properties for identified groups. The contribution of assessed properties to each principal component (PC) is illustrated in the graph to the left. Correlation of individual cells plotted on the same axes (right graph) reveals that initial firing frequency and frequency adaptation most strongly identify Group 3, with Groups 1 and 2 being distributed along the same PC axis.

$\left(3 \mathrm{ml} / \mathrm{min}\right.$ at $\left.30^{\circ} \mathrm{C}\right)$. Borosilicate patch electrodes had an open tip resistance of 3-6 $\mathrm{M} \Omega$ when filled with an intracellular solution containing (in $\mathrm{mM}$ ): $125 \mathrm{~K}$-gluconate, $10 \mathrm{KCl}, 10 \mathrm{HEPES}$, 10 creatine- $\mathrm{PO}_{4}, 2 \mathrm{Mg}$-ATP, $0.2 \mathrm{Na}-\mathrm{GTP}, 0.5$ EGTA, which had an adjusted $\mathrm{pH}$ and osmolarity of 7.3 and 290, respectively. For a subset of control experiments, a cesium-based internal solution was used containing (in mM): $129 \mathrm{CsCl}, 10$ HEPES, $2 \mathrm{Mg}$-ATP, $0.2 \mathrm{Na}-\mathrm{GTP}, 10$ EGTA, which had an adjusted $\mathrm{pH}$ and osmolarity of 7.3 and 290, respectively. Tight seals of 1 G $\Omega$ or greater were obtained under visual guidance before breaking into whole-cell mode. INs in L1 were identified by their proximity to the pial surface and the low density of cells within L1 compared to layer $2 / 3$.

\section{Intrinsic Properties}

Several intrinsic properties of neurons, specifically: resting membrane potential (RMP), action potential (AP) height, AP half-width, AP threshold, after-hyperpolarization (AHP) amplitude, time to AHP peak (tAHP), initial firing frequency, and frequency adaptation were recorded for use in cluster analysis. Input resistance $\left(R_{\mathrm{IN}}\right)$ was not included as a variable for cluster analysis as the drastic developmental changes in $R_{\mathrm{IN}}$ caused cells to be grouped solely based on the postnatal day at which they were recorded. RMP was calculated from a minimum of five records at the membrane potential in the absence of network activity or stimulation. AP and AHP properties were calculated from the first AP fired in response to depolarizing current injected in $50 \mathrm{pA}$ steps. AP threshold was identified as the potential at which rapid membrane depolarization began. AP height was calculated from threshold to the peak amplitude before repolarization, and AP half-width was defined as the width of the AP at half-maximum amplitude. AHP amplitude and tAHP were defined as the most hyperpolarized potential reached following an AP and the time to peak following return to RMP upon repolarization, respectively. Initial firing frequency and frequency adaptation were calculated from responses to current injection double the rheobase amplitude. Initial firing frequency was calculated as the reciprocal of the first interspike interval (ISI), and frequency adaptation was defined as the percent change in ISI from the first to last spikes (1st ISI-last ISI/1st ISI). $R_{\mathrm{IN}}$ was calculated using Ohm's law from the voltage deflection in response to a $-50 \mathrm{pA}$ current injection.

\section{Morphological Reconstruction}

Biocytin (0.5\%; Sigma, St. Louis, MO, USA) or Alexa Fluor 594 hydrazide (0.075\%; Molecular Probes, Eugene, OR, USA) 

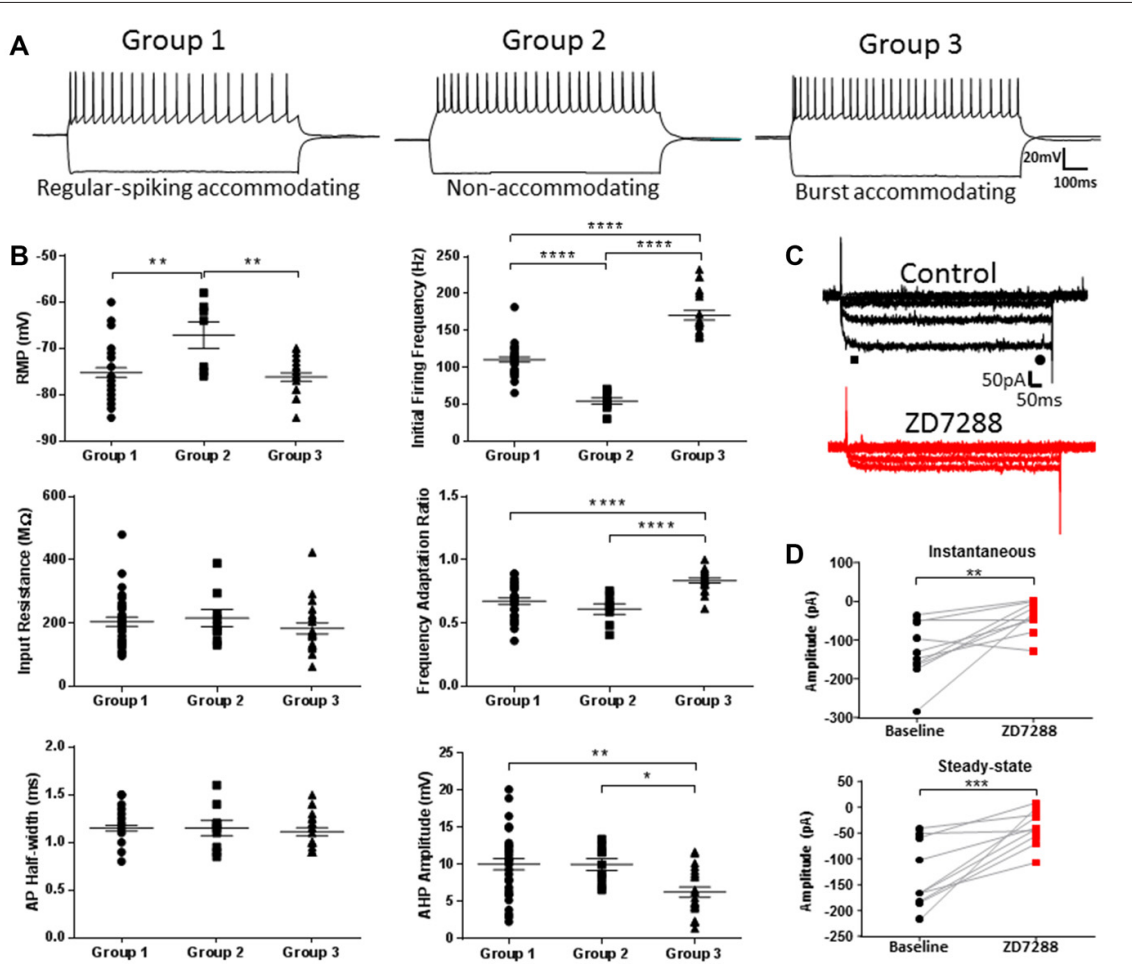

FIGURE 2 | Characterization of identified L1 IN populations. (A) Representative examples of the firing patterns observed for each of the cell groups shown in Figure 1. (B) Quantitative comparison of intrinsic properties in the cell groups including initial firing frequency and frequency adaptation, consistent with PLS-EDA results. (C) Example traces of hyperpolarization-activated current $(/ h)$ recordings before (black, top) and after (red, bottom) wash-on of $20 \mu M$ ZD7288. Instantaneous and steady-state currents were measured at the peak after current onset and immediately prior to current offset, as indicated by the black bar and circle, respectively. (D) Plots showing peak instaneous and steady state current amplitudes before and after ZD7288. Hyperpolarization-activated, cyclic nucleotide-gated, non-specific cation $(\mathrm{HCN})$ channel inhibition produced a decrease in both currents indicative of the presence of a small amplitude $I_{\mathrm{h}}$ current in L1 INs. ${ }^{*} p<0.05$, ${ }^{* *} p<0.01,{ }^{* * *} p<0.001,{ }^{* * * *} p<0.0001$, Tukey's post-test. Each shape represents an individual cell. Error bars are mean \pm SEM.

was added to the intracellular solution in some experiments for post hoc morphological analysis. Slices with biocytin-filled cells were processed as previously described (Zhou and Hablitz, 1996a). Slices with Alexa Fluor filled cells were fixed in paraformaldehyde at $4^{\circ} \mathrm{C}$ for $48 \mathrm{~h}$ then mounted to slides for imaging. Fluorescently labeled cells were imaged using a Zeiss LSM 510 confocal microscope (Carl Zeiss Inc., Thornwood, NY, USA) using a 605/670 bandpass emission filter. Images were acquired using Zen software (Zen Software Inc., Trumbull, CT, USA) and further processed using ImageJ (U.S. NIH, Bethesda, MD, USA) and Photoshop (Adobe Systems Inc., San Jose, CA, USA). L1 INs with an axon extending $>200 \mu \mathrm{m}$ from the pial surface (or $>100 \mu \mathrm{m}$ into layer II/III) were classified as deep-projecting whereas cells with axons projecting laterally within L1 were termed horizontally projecting. Using that criteria, a chi-squared test was performed to determine if neuronal physiology and type of axon projection are independent properties.

\section{Data Acquisition and Analysis}

Whole-cell recordings were obtained using an ELC-03XS npi bridge balance amplifier (npi Electronic GmbH, Tamm, Germany). Signals were acquired using Clampex software with a Digidata 1322A interface (Molecular Devices). Evoked responses were digitized at $10 \mathrm{kHz}$, filtered at $2 \mathrm{kHz}$ and analyzed using Clampfit 9.0 software (Molecular Devices). Synaptic responses were evoked using a nichrome bipolar electrode positioned in $\mathrm{L} 2, \sim 100 \mu \mathrm{m}$ from the recording electrode, using $10-100 \mu \mathrm{A}$ current pulses of $100 \mu \mathrm{s}$ duration. EPSP summation was calculated as the percent change in the amplitude of the fifth evoked event relative to the amplitude of the first event. Area under the curve (AUC) of evoked trains was calculated from the onset of the first stimulation until return to RMP following the fifth stimulation. AUC was normalized to the amplitude of the first EPSP to account for changes in input, as stimulus intensity was kept constant for pre- and post-drug trials. Both summation and AUC were initially analyzed across all frequencies, using a post-test to identify frequency-specific effects. In a set of control experiments, EPSCs were recorded from L1 INs held at $-70 \mathrm{mV}$ to eliminate voltage-dependent changes in HCN channel activity. Miniature event analysis was performed using MiniAnalysis (Synaptosoft). An equal number of consecutive events was taken from each recorded cell for analysis.

\section{Drugs and Drug Application}

Bicuculline-methiodide (10 $\mu \mathrm{M}$; Abcam, Cambridge, MA, USA) or SR95531-hydrobromide (10 $\mu \mathrm{M}$; Tocris, Ellisville, 

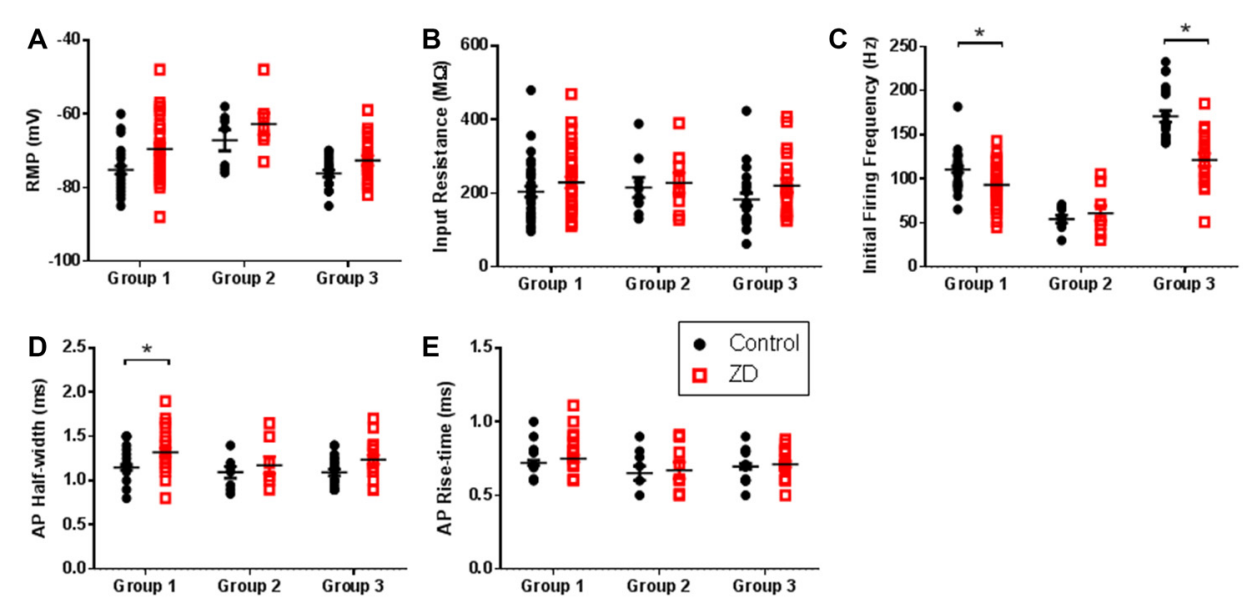

FIGURE 3 | HCN channel inhibition exerts cell-type specific effects on intrinsic excitability. Scatter plots showing (A) the resting membrane potential (RMP), (B) input resistance $\left(R_{\mathbb{I N}}\right)$, (C) initial firing frequency, (D) action potential (AP) half-width and (E) AP rise time of cells in each group before (black circles) and after (red squares) wash-on of the HCN channel antagonist ZD7288. Group 1 showed the largest effects whereas Group 2 cells displayed no modulation of intrinsic excitability by HCN channels. ${ }^{*} p<0.05$, paired $t$-test. Each shape represents an individual cell. Error bars are mean \pm SEM.

MO, USA) was present in the saline for all experiments to block $\mathrm{GABA}_{\mathrm{A}}$ receptor mediated synaptic transmission. After recording control responses, 4-Ethylphenylamino-1,2-dimethyl6-methylaminopyrimidinium chloride $(20 \mu \mathrm{M}$; ZD7288; Tocris Bioscience, Ellisville, MO, USA) was washed in for $10 \mathrm{~min}$ to block HCN channels. ZD7288 was applied at a $10 \mu \mathrm{M}$ concentration in a set of control experiments in order to rule out dose-dependent, off-target effects. In another set of control experiments, $20 \mu \mathrm{M}$ ZD7288 was added to the normal K-gluconate internal solution for cell-specific, post-synaptic HCN channel inhibition. Tetrodotoxin-citrate (1 $\mu \mathrm{M}$; Sigma, St. Louis, MO, USA) was used to block AP mediated synaptic transmission for the analysis of mEPSCs. All drugs were bath applied unless otherwise stated, with each neuron serving as its own control.

\section{Statistics}

Statistical analysis of electrophysiological data was performed using GraphPad Prism 6 (La Jolla, CA, USA). Data are expressed as either mean \pm SEM or dots representing each individual data point. Traces shown are the average of 10 sweeps. Sample size (n) is the number of cells used for each experiment, with a minimum of three animals used per group. Statistical comparisons of responses before and during drug application was performed using a one- or two-tailed Student's $t$-test, or Two-way ANOVA with a Sidak correction for multiple comparisons. For all tests, $p<0.05$ was considered significant.

Unbiased hierarchical cluster analysis using the Ward method with a Euclidean distance metric was performed with R-based software (Wessa, 2012), and partial least squared enhanced discrimination analysis (PLS-EDA) was performed using the Excel add-in Multibase package (Numerical Dynamics, Japan). The cutoff for determining the number of clusters was determined by the exponential decay in the Euclidean distance between branch points. All variables were normalized to their $z$ score for PLS-EDA. Aside from frequency adaptation and firing frequency $\left(r^{2}=0.42\right)$, all properties used for cluster analysis were weakly correlated to one another $\left(r^{2}<0.23\right)$.

\section{RESULTS}

\section{Unbiased Clustering of Mature L1 INs}

In this study, we analyzed electrophysiological properties of L1 INs in rat AGm in order to identify and characterize distinct cell groups within L1. Using hierarchical clustering based on a set of eight active and passive membrane properties which are commonly used to differentiate neuronal subtypes, we were able to identify three distinct L1 cell types in the adult AGm (Figure 1A). Each terminal dendrogram branch represents an individual L1 neuron. The height (Figure 1A, Y-axis) of branching points reflects the physiological similarity of groups/cells with larger height values indicating a larger degree of dissimilarity. PLS regression was then performed to confirm that the clusters represented physiologically distinct groups and to identify the key differentiating characteristics. The contribution of assessed properties to each PC is shown in Figure 1B, left. When the correlation of individual cells was plotted on the same axes (Figure 1B, right) initial firing frequency and frequency adaptation most strongly identify Group 3, with Groups 1 and 2 being distributed along the same PC axis. PLS analysis suggested cell clusters were most strongly differentiated based on initial firing frequency and spike frequency adaptation.

Quantitative comparison of firing properties between groups supported the finding that firing frequency and adaptation defined each cell type (Figure 2A; Initial firing frequency-Group 1: $110.4 \pm 3.5 \mathrm{~Hz}$, Group 2: $54.2 \pm 4.3 \mathrm{~Hz}$, Group 3: $170.7 \pm 6.4 \mathrm{~Hz} ; p<0.0001$, 1-way ANOVA; Spike frequency adaptation-Group 1: $0.67 \pm 0.03$, Group 2: $0.61 \pm 0.04$, Group 3: $0.84 \pm 0.02 ; p<0.0001$, 1-way 

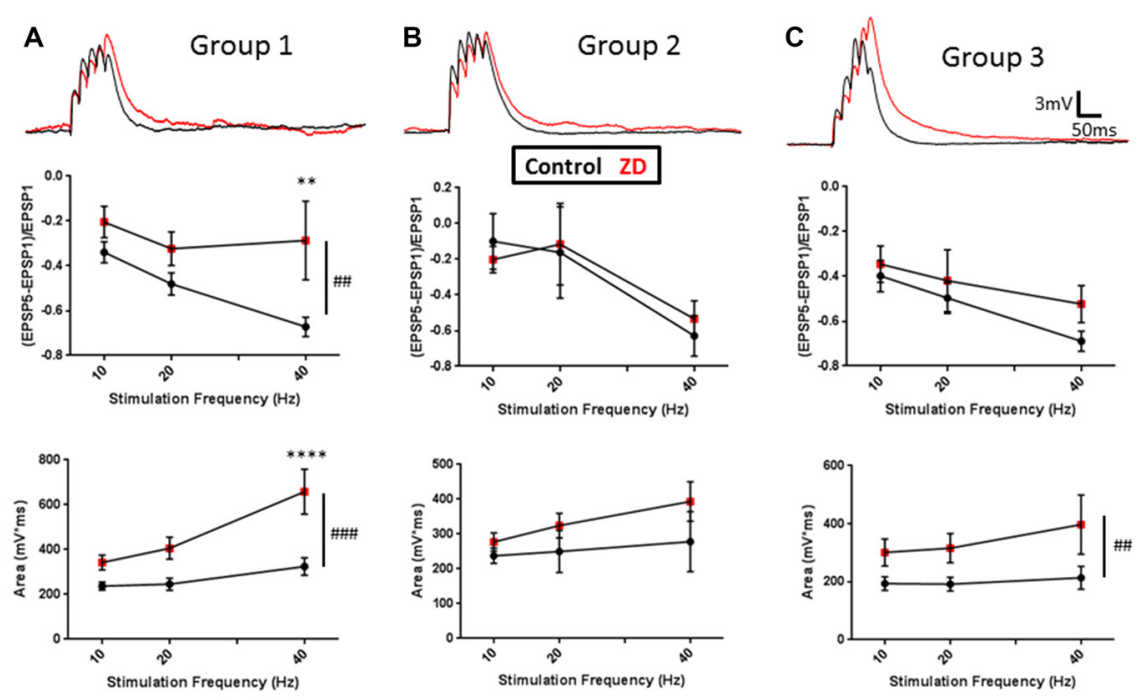

FIGURE 4 | Cell-group dependent effects of HCN channel inhibition on synaptic excitability. (A) Upper: representative examples of evoked EPSPs before (black) and after (red) bath application of ZD7288. Middle: plots of EPSP ratios before (black) and after (red) ZD7288 wash-on. Lower: plot of total area under the curve (AUC) of EPSPs evoked under control conditions (black) and in the presence (red) of ZD7288. (B,C) Same as in (A) but for Groups 2 and 3, respectively. As with intrinsic excitability, group-specific effects were observed, with Group 1 showing the largest effects and Group 2 cells displaying no modulation by HCN channels.

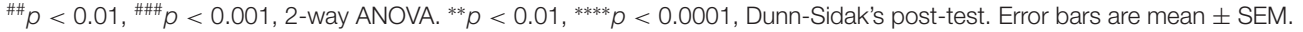

ANOVA). No differences in AP threshold, AP height or tAHP were seen between groups. Based on their intrinsic properties, the three groups were classified as Group 1, regular spiking (RS), Group 2, non-accommodating (NA) and Group 3, burst accommodating (BA), respectively (Figure 2B).

Figure 2C shows responses of a L1 IN to a family of hyperpolarizing voltage steps under control condition and after HCN channel blockade with ZD7288. Instantaneous and steady-state currents associated with $I_{\mathrm{h}}$ are shown in Figure 2C. Using the HCN channel inhibitor ZD7288, we were able to confirm the presence of small amplitude $I_{\mathrm{h}}$ in L1 INs (Figure 2D; Instantaneous-Control: $128.57 \pm 23.71 \mathrm{pA}$, ZD7288: $39.15 \pm 12.86 \mathrm{pA} ; p<0.01$, paired $t$-test; Steadystate-Control: $132.97 \pm 20.19 \mathrm{pA}$, ZD7288: $38.73 \pm 10.92 \mathrm{pA}$; $p=0.0001$, paired $t$-test). The measured $I_{\mathrm{h}}$ amplitude was small compared to currents previously observed in L5 pyramidal neurons (PNs; Albertson et al., 2011) and GABAergic INs (Albertson et al., 2017). The voltage "sag" response characteristic of $I_{\mathrm{h}}$ was also quantified to assess differences in functional HCN channel expression between groups. A small HCN channel mediated sag was observed in each cell-type, however no differences were seen between groups (data not shown; Time-current amplitude interaction: $p=0.9822$, 2-way ANOVA).

\section{Differential Modulation of the Excitability of Mature L1 INs by HCN Channels}

HCN channels have been shown to modulate various intrinsic neuronal properties in a cell-specific manner (Robinson and Siegelbaum, 2003; Biel et al., 2009). Having established the presence of $I_{\mathrm{h}}$, we bath applied ZD7288 to determine the role of HCN channels in modulating the intrinsic excitability of identified AGm L1 IN groups. As shown in Figures 3A,B, application of ZD7288 did not produce a significant RMP hyperpolarization (RS-Control: $-75.2 \pm 1.0 \mathrm{mV}$, ZD7288: $-69.5 \pm 1.5 \mathrm{mV} ; p>0.05$, 1-tailed $t$-test; NA-Control: $-67.1 \pm 2.9 \mathrm{mV}$, ZD7288: $-62.7 \pm 2.9 \mathrm{mV} ; p>0.05$, 1-tailed $t$-test; BA-Control: $-76.2 \pm 0.9 \mathrm{mV}$, ZD7288: $-72.6 \pm 1.4 \mathrm{mV}$; $p>0.05,1$-tailed $t$-test) or increase in $R_{\mathrm{IN}}$ (RS-Control: $204.26 \pm 14.7 \mathrm{M} \Omega$, ZD7288: $229.23 \pm 15.6 \mathrm{M} \Omega$; $p>0.05$, 1-tailed $t$-test; NA-Control: $215.46 \pm 27.2 \mathrm{M} \Omega$, ZD7288: $227.57+27.5 \mathrm{M} \Omega ; p>0.05,1$-tailed $t$-test ; BA-Control: $182.86 \pm 17.2 \mathrm{M} \Omega$, ZD7288: $220.4 \pm 17.6 \mathrm{M} \Omega ; p>0.05$, 1-tailed $t$-test) for any cell type. The initial firing frequency of both RS and BA groups were decreased following ZD7288 application (RS-Control: $110.4 \pm 3.5 \mathrm{~Hz}$, ZD7288: $92.9 \pm 4.2 \mathrm{~Hz} ; p<0.01$, Holm-Sidak test; BA-Control: $170.7 \pm 6.4 \mathrm{~Hz}$, ZD7288: $121.4 \pm 7.1 \mathrm{~Hz} ; p<0.0001$, Holm-Sidak test), with no effect observed on NA neuron firing rate (Control: $54.2 \pm 4.3 \mathrm{~Hz}$, ZD7288: $60.8 \pm 8.5 \mathrm{~Hz} ; p=0.5$, Holm-Sidak test; Figure 3C). In addition, HCN channel inhibition caused a significant increase in the AP half-width of RS neurons (Control: $1.15 \pm 0.03 \mathrm{~ms}$, ZD7288: $1.32 \pm 0.1 \mathrm{~ms} ; p<0.01$; Holm-Sidak test) without affecting the AP rise time (Control: $0.72 \pm 0.02 \mathrm{~ms}$, ZD7288: $0.75 \pm 0.02 \mathrm{~ms} ; p=0.32$, Holm-Sidak test; Figures 3D,E).

Extensive work has also described a role for HCN channels in modulating the integration of synaptic inputs to neurons (Stuart and Spruston, 1998; Williams and Stuart, 2000; Berger et al., 2001; Albertson et al., 2011). These studies have shown that the density and distribution of HCN channels across a cell's processes can affect frequency dependent filtering and spatial integration of synaptic inputs. To characterize the 


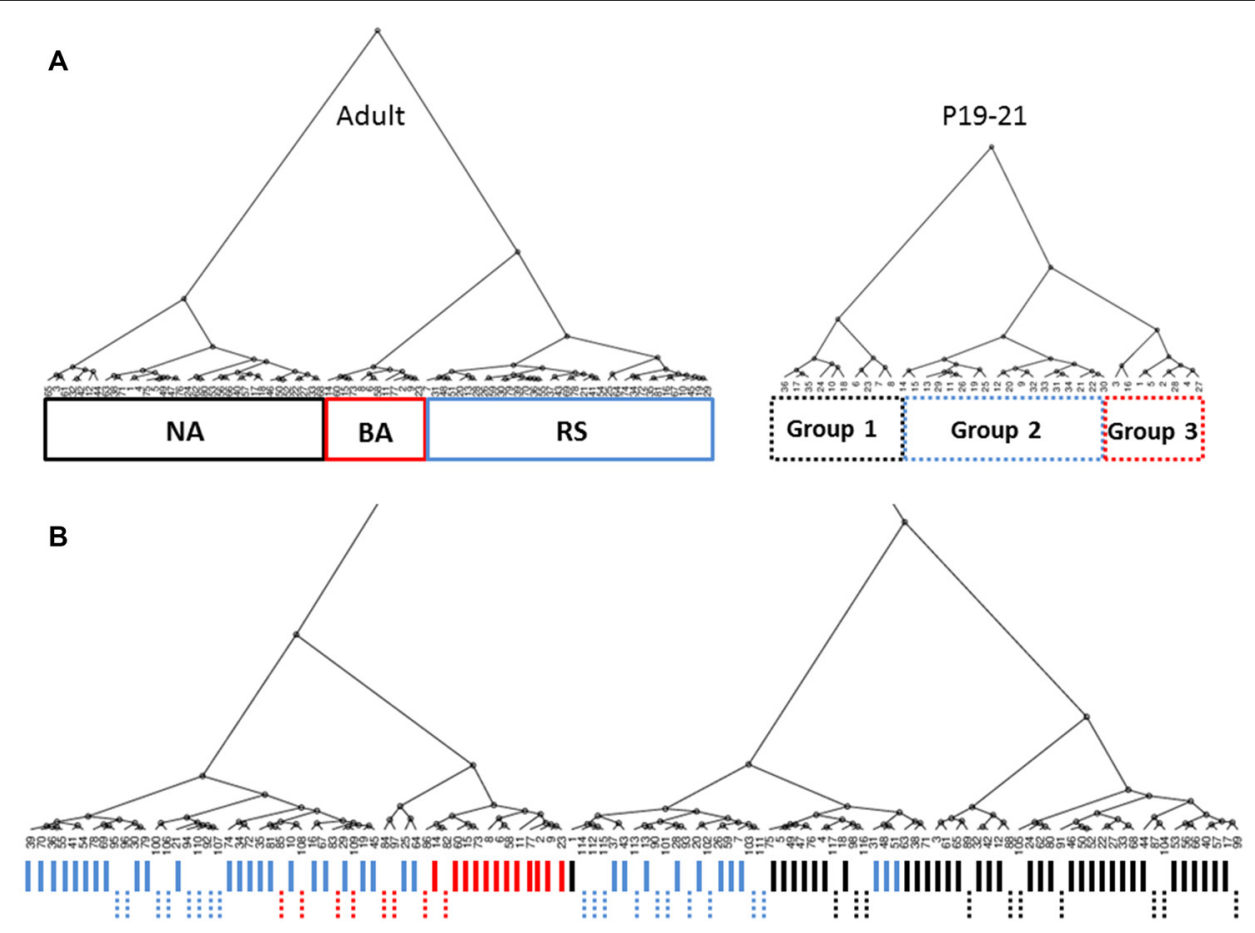

FIGURE 5 | Cell groups can be tracked throughout development. (A) Dendrograms generated by unbiased hierarchical cluster analysis of the electrophysiological properties of cells recorded from adult animals (left) and P19-21 (right) animals. Three distinct groups are identified in both age groups. As with the adult groups, PLS analysis identified initial firing frequency and frequency adaptation as key determinants of neuronal grouping at P19-21. (B) Combined analysis of Adult and

P19-21 animals reveals overlap between cell groups identified at chronologically sequential ages, indicating cell groups in adult animals can also be identified at younger ages. Solid and dashed lines indicate cells from adult and P19-21 animals, respectively. Line colors in (B) coincide with the line color of group outlines shown in (A).

contribution of HCN channels to the synaptic excitability of L1 INs, we evaluated the effect of ZD7288 application on the integration of synaptic responses evoked at 10,20 and $40 \mathrm{~Hz}$ (Figure 4). Synaptic integration was evaluated by quantifying EPSP amplitude summation as well as the total area under the curve of evoked activity (AUC). Specimen records of EPSPs evoked in RS, NA and BS cells are shown in upper portions of Figures 4A-C, respectively. In RS Group 1 cells, inhibition of $\mathrm{HCN}$ channels significantly increased synaptic summation $(p<0.01,2$-way ANOVA $)$ and AUC $(p<0.0001,2$-way
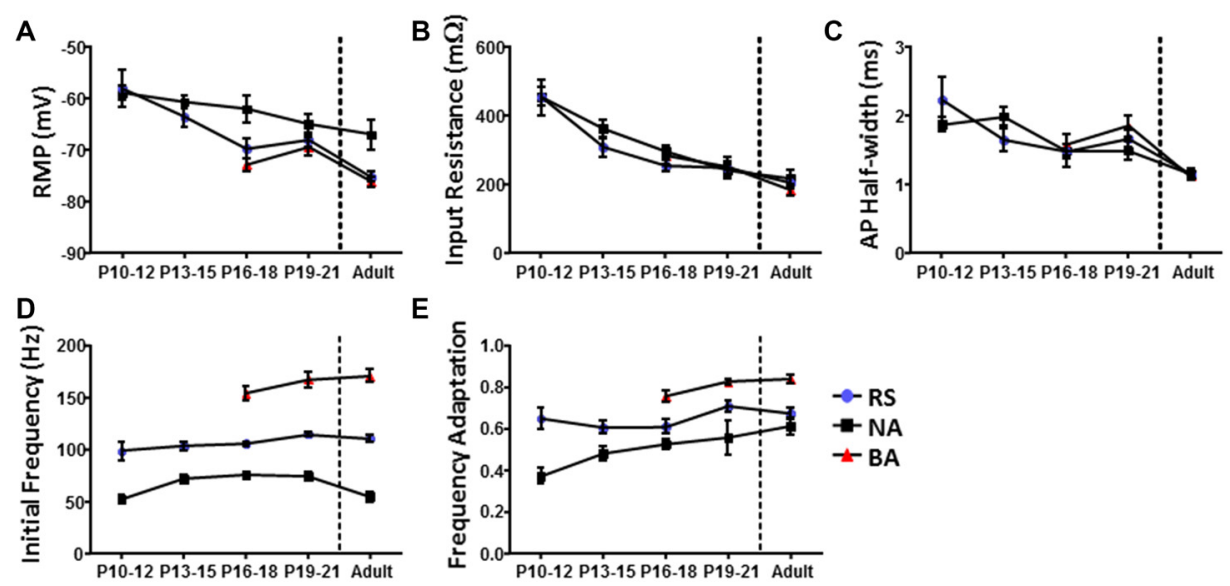

FIGURE 6 | Identified L1 IN groups display distinct intrinsic properties throughout development. Graphs illustrating differences in the (A) RMP, (B) $R_{\mathbb{N}}$, (C) AP half-width, (D) initial firing frequency and (E) frequency adaptation of cells in each group as a function of development. Comparison of intrinsic properties across groups suggests a specific distinction between non-accommodating (NA) cells and the other groups. Error bars are mean \pm SEM. 


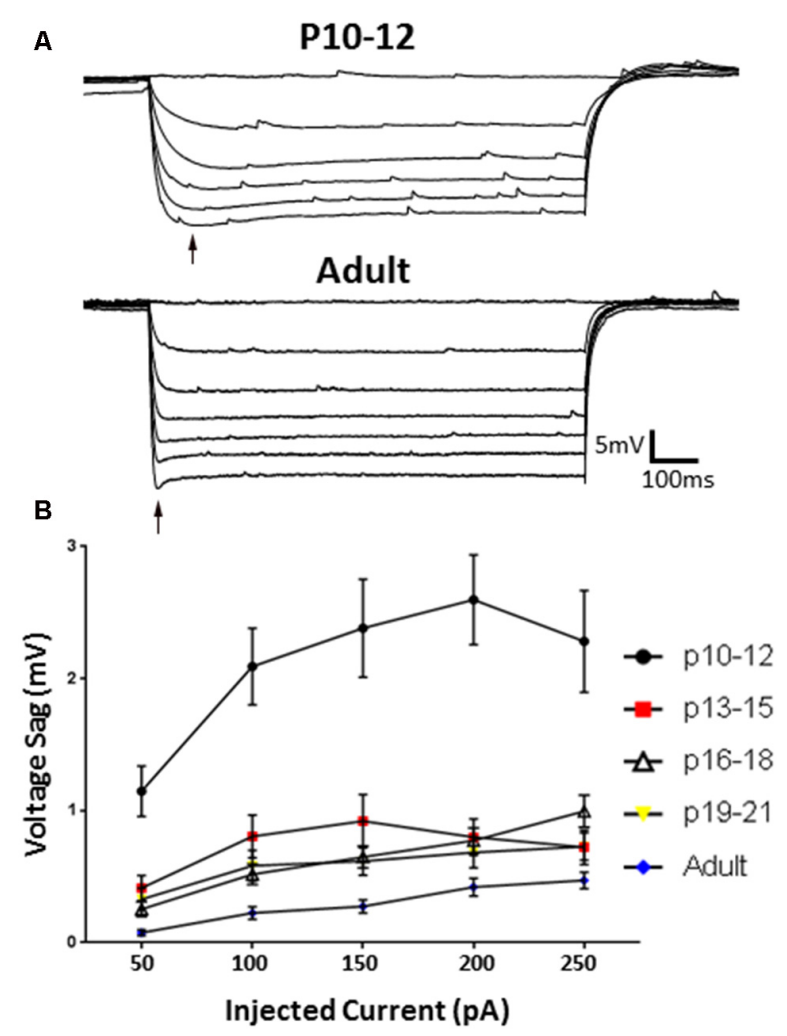

FIGURE 7 | HCN channel-mediated sag responses change with development. (A) Example traces of the sag responses from a P10-12 IN (top) and adult (bottom) animals. (B) The $/ \mathrm{h}$-associated voltage sag is significantly larger at P10-12, and significantly smaller in adult cells, indicating developmental regulation of $\mathrm{HCN}$-mediated effects. Black arrow indicates sag. Error bars are mean \pm SEM.

ANOVA), particularly with $40 \mathrm{~Hz}$ input (Summation: $p<0.01$, Sidak post-test; AUC: $p<0.0001$, Sidak post-test; Figure 4A, middle and lower). In contrast, $\mathrm{HCN}$ channels inhibition did not have any effect on the summation ( $p=0.9277,2$-way ANOVA) or AUC ( $p=0.0854,2$-way ANOVA) of EPSPs in Group 2 NA cells (Figure 4B). The synaptic integration of BS Group 3 cells demonstrated moderate $\mathrm{HCN}$ channel modulation, showing a significant increase in the AUC ( $p<0.01,2$-way ANOVA), but no observable increase in the summation of EPSPs $(p=0.1729$, 2-way ANOVA) following ZD7288 application (Figure 4C). In combination with the distinct effects of ZD7288 on the intrinsic properties of identified groups, these results suggest HCN channels modulate the excitability of RS and BA cells, but do not significantly affect NA neurons in the adult AGm.

In addition to effects on neuronal excitability, HCN channels have also been shown to modulate presynaptic neurotransmitter release in certain cells populations (Santoro et al., 1997; Southan et al., 2000; Cuttle et al., 2001; Aponte et al., 2006). To determine if effects observed upon ZD7288 application were due to a postsynaptic effect, we examined presynaptic neurotransmitter release by assessing the amplitude and frequency of miniature EPSCs onto L1 INs, as well as the paired-pulse ratio (PPR) of evoked EPSCs. No changes were observed in the frequency (Control: $0.92 \pm 0.18 \mathrm{~Hz}, \mathrm{ZD} 7288$ : $0.98 \pm 0.18 \mathrm{~Hz} ; p>0.999$, Kolmogorov-Smirnov test) or amplitude (Control: $20.11 \pm 0.99$ pA, ZD7288: $10.09 \pm 0.99$ pA; $p=0.998$, Kolmogorov-Smirnov test) of miniature EPSCs (data not shown). Moreover, ZD7288 had no effect on the PPR of EPSCs evoked at $25 \mathrm{~ms}$ (Control: $0.83 \pm 0.1$, ZD7288: $0.95 \pm 0.1 ; p=0.143$, paired $t$-test), $50 \mathrm{~ms}$ (Control: $0.87 \pm 0.1$, ZD7288: $0.96 \pm 0.1 ; p=0.237$, paired $t$-test) or $100 \mathrm{~ms}$ (Control: $0.85 \pm 0.1$, ZD7288: $0.97 \pm 0.1 ; p=0.152$, paired $t$-test) intervals, suggesting any effects of ZD7288 were post synaptic. To further confirm a post-synaptic mechanism of action for ZD7288, summation experiments were performed using a modified intracellular solution containing either $\mathrm{Cs}^{+}$, a non-specific HCN channel blocker, or ZD7288 to specifically block post-synaptic HCN channels. Under both conditions, the effects of ZD7288 on $40 \mathrm{~Hz}$ EPSP summation $\left(\mathrm{Cs}^{+}-\right.$Control: $-0.39 \pm 0.4$, ZD7288: $-0.75 \pm 0.1 ; p=0.30$, paired $t$-test; Intracellular ZD7288-Control: $-0.61 \pm 0.1$, ZD7288: $-0.49 \pm 0.1 ; p=0.08$, paired $t$-test) were abrogated (data not shown), suggesting a post-synaptic basis for the changes in synaptic excitability observed following HCN channel inhibition.

\section{Classification of L1 INs during Development}

It is well known that synaptic activity during development shapes cortical connectivity effecting changes that will persist into adulthood. Recent work has shown that HCN channel expression and function can display developmental changes, conferring varying patterns of excitability modulation (Surges et al., 2006; Bender and Baram, 2008; Cho et al., 2011; Seo et al., 2015). We therefore sought to determine if the effects of $\mathrm{HCN}$ channels on L1 IN excitability were developmentally regulated.

CR cells constitute the majority of the neuronal population found in L1 during the first postnatal week (Bradford et al., 1978; Chun and Shatz, 1989; Zhou and Hablitz, 1996b). Since the presence of CR cells is transient, virtually disappearing by postnatal day 14 (P14), the developmental time course of HCN channel effects was characterized from P10 to P21 in order to assess cell-types in which the effect of HCN channels could be evaluated into adulthood. Under these restrictions we could reasonably presume that neurons recorded at the youngest age would ultimately develop into one of the cell-types identified in adult animals. Based on the time course of changes in the intrinsic properties of L1 INs (data not shown), developmental data was grouped into three-day bins for analysis: P10-12, P13-15, P16-18 and P19-21.

Currently available methods do not allow for chronic whole-cell recordings from a single neuron across the developmental range investigated here. Therefore, identification of specific cell-types throughout development was performed using cluster analysis and PLS as was done for cells from adult animals. Cluster analysis was first performed within each 3 day group to definitively identify cell clusters at each age. Figure 5A shows dendrograms generated by unbiased hierarchical cluster analysis of the electrophysiological properties of cells recorded from adult animals (left) and P19-21 (right) animals. To 

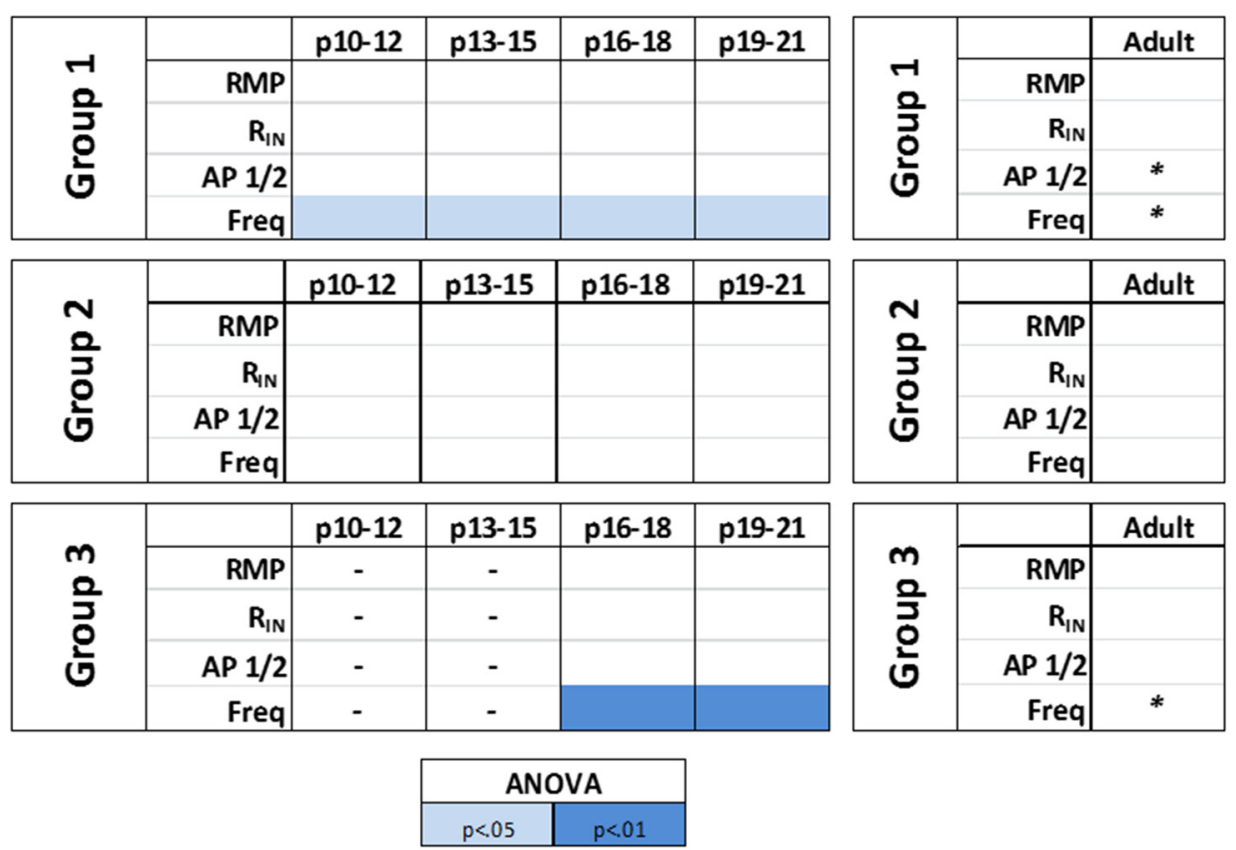

FIGURE 8 | HCN channels differentially modulate the intrinsic excitability of identified L1 IN groups over development. A summary of the effects of HCN channels blockade on the intrinsic properties of identified cell groups throughout development. A small contribution of HCN channels to the intrinsic excitability of L1 INs was observed with HCN channel inhibition producing a significant decrease in the initial frequency of regular spiking (RS) and burst accommodating (BA) neurons across their developmental ranges but not affecting the excitability of NA cells at any age. Statistical comparison was performed on values obtained before and after ZD7288 wash-on. * $p<0.05$, paired $t$-test.

confirm identified groups represented the same cell populations throughout development, cluster analysis was then performed in reverse chronological order combining sequential age groups, as shown in Figure 5B for the Adult and P19-21 groups. Using this method, the RS and NA clusters identified in adult animals could be traced throughout development back to P10, with BA cells emerging at P16. As with the adult groups, PLS analysis identified initial firing frequency and frequency adaptation as key determinants of neuronal grouping at all ages, consistent with identified clusters representing cell types which are present throughout development. Comparison of intrinsic properties across groups revealed a specific distinction between NA cells and the other groups (Figure 6). Specifically, NA cells displayed a more depolarized RMP (Figure 6A) and lower firing frequency (Figure 6D) throughout development. BA cells exhibited a significantly higher firing frequency than both RS and NA cells (Figure 6D), but did not differ from RS cells in any other properties. Due to the similarity of their intrinsic properties, it is possible that BA neurons represent a subset of RS cells which developmentally differentiates based on the expression of channels which facilitate the higher firing frequency.

\section{Distinct Patterns of HCN Channel Excitability Modulation in L1 Throughout Development}

Having confirmed identified clusters persist during development, we next assessed whether L1 INs displayed developmental changes in HCN channel mediated sag amplitude (Figure 7). Specimen records of responses to a series of hyperpolarizing current pulses are shown in Figure 7A for a P10-12 (upper) and adult (lower) group neuron. INs recorded at P10-12 displayed a significantly larger voltage sag then observed at all other ages $(p<0.0001$, Tukey's test), with adult neurons displaying the smallest sag (Figure 7B; $p<0.01$, Tukey's test). Sag amplitude stabilized following P12, with no difference being observed between any other developmental age groups. At P13-15 the voltage sag of NA neurons was significantly larger than that of RS neurons ( $p<0.0001,2$-way ANOVA), though no difference between groups persisted throughout the entire developmental time course.

The effects of HCN channels on intrinsic excitability throughout development were then examined. As summarized in Figure 8, HCN channel inhibition resulted in a significant decrease in the initial frequency of RS and BA neurons across their developmental ranges, but did not affect the firing of NA cells. Consistent with data from adult cells, application of ZD7288 did not produce membrane hyperpolarization or an increase in $R_{\mathrm{IN}}$ in any group during development.

The modulatory effects of HCN channels on synaptic integration throughout development were also examined. In RS cells, modulation by HCN channels increased developmentally (Figure 9). HCN channel inhibition had no effect on synaptic excitability at the youngest age recorded (Figure 9A), caused a significant increase in summation but not AUC at P13-15 


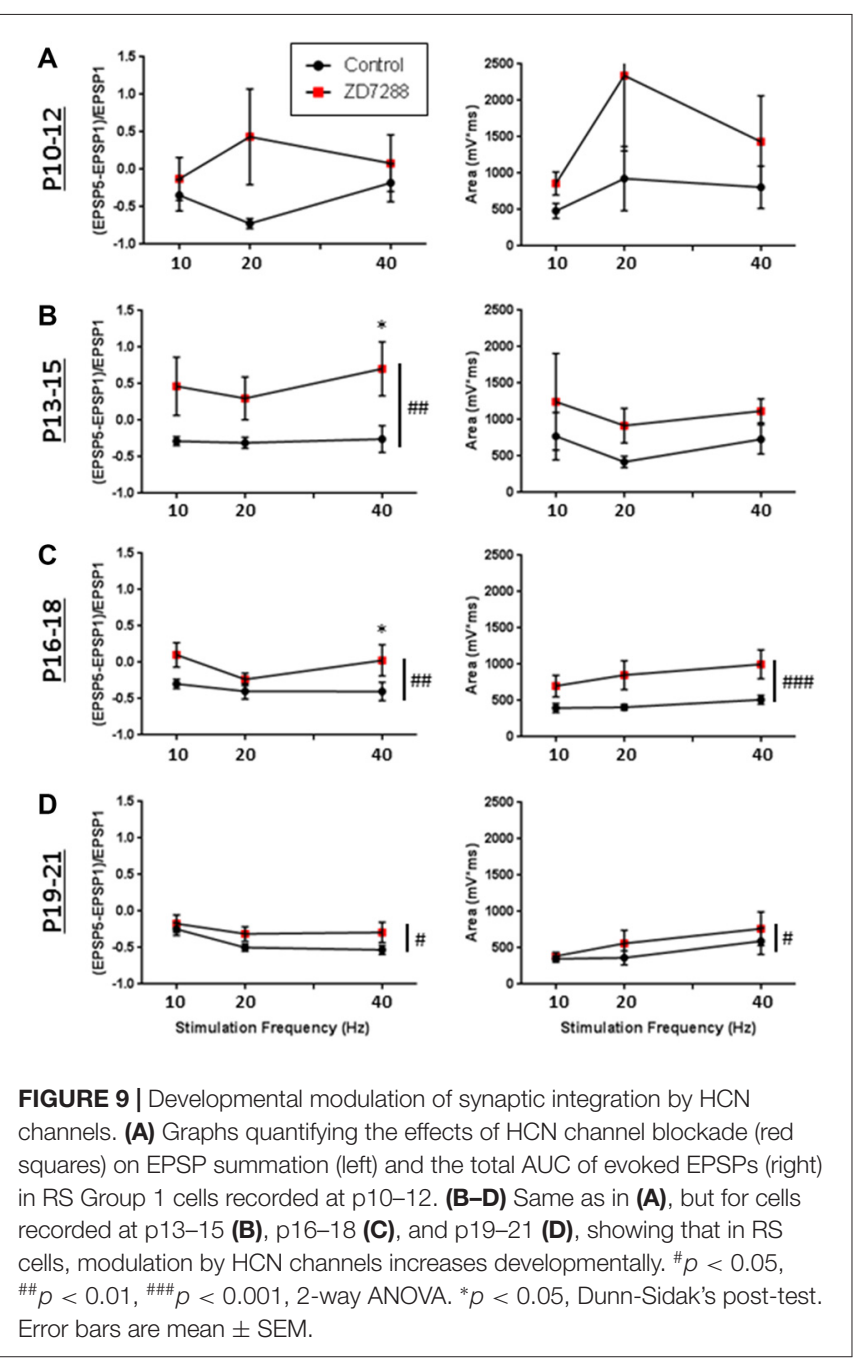

(Figure 9B), and from P16 to P21 significantly increased both summation and AUC (Figures 9C,D). In stark contrast, we found the effects of HCN channel inhibition displayed a pattern of decreasing significance throughout development in NA neurons (Figure 10). In NA cells at P10-12 inhibition of HCN channels caused the largest change in summation and AUC seen for any group at any age. Summation and AUC were both significantly affected by $\mathrm{HCN}$ channel inhibition for NA cells at P13-15 and P16-18, with the magnitude of observed changes becoming progressively smaller with age. In P19-21 NA cells, inhibition of HCN channels caused a small, significant increase in summation, but had no effect on AUC. BS cells demonstrated modulation by HCN channels similar to that seen in RS cells. Both the summation and AUC of EPSPs were significantly increased in BS neurons at P16-18 and P19-21 (Figure 10). Viewing developmental data together with data generated from adult cells, clear developmental patterns of HCN channel modulation emerge, with modulation increasing and decreasing with age in RS and NA cells, respectively (Figure 10). As with cells from mature animals, HCN channel inhibition had no effect on the frequency of mEPSCs, again suggesting changes seen in the presence of ZD7288 are due to a postsynaptic effect.

\section{Morphology of L1 IN Groups Is Correlated with Physiology}

Morphological analysis was performed in a subset of BA and NA cells (Figure 11A) from adult animals to further validate that the identified cell clusters represent distinct neuronal groups. Blinded to physiological grouping, post hoc reconstructed L1 INs were morphologically classified as either deep projecting or horizontally projecting, as described by Jiang et al. (2013) and Lee et al. (2015) (Figure 11B). A significant correlation between morphology and physiology was identified $\left(\chi^{2}: p<0.01\right)$, with a distinct deep projecting axon being identified in a larger percentage of $\mathrm{BA}$ cells $(\mathrm{BA}=11$ of $14, \mathrm{NA}=1$ of 8$)$, while a greater portion of NA cells were definitively identified as horizontally projecting ( $\mathrm{BA}=1$ of $14, \mathrm{NA}=3$ of 8 ). Cells for which a clear classification could not be determined were not included in either group. This finding is consistent with previous data suggesting the physiological properties of L1 INs can be used to identify discrete cell groups (Wozny and Williams, 2011; Jiang et al., 2013).

\section{DISCUSSION}

In the present study we investigated the modulatory influence of HCN channels on the intrinsic and synaptic excitability of AGm L1 INs throughout development. Our studies revealed two distinct groups which display divergent patterns of $\mathrm{HCN}$ channel modulation during development. We found that $\mathrm{HCN}$ channel inhibition altered the repetitive firing properties of RS neurons across every age, whereas no effects on the intrinsic excitability of NA neurons were seen. RS cells also displayed a pattern of gradually increasing modulation of synaptic excitability with age. Conversely, NA neurons evidenced decreased modulation by HCN channels over time. A third cell-type physiologically characterized as BS neurons was also identified beginning at p16. BS cells displayed morphological and physiological characteristics similar to those of RS cells. The influence of HCN channel inhibition on the excitability of BS cells closely resembled that of RS cells, suggesting BS cells may represent a subset of RS neurons differentiated by channel expression.

\section{Effect of IN Excitability on Cortical Output}

In the neocortex, GABAergic INs are the primary source of inhibition and serve to regulate glutamate-driven network output (Markram et al., 2004; Silberberg, 2008; Hu et al., 2014). Extensive studies characterizing cortical GABAergic INs have revealed multiple IN classes which display unique intrinsic properties and synaptic targets (DeFelipe, 1993; Cauli et al., 1997; Kawaguchi and Kubota, 1997; Gupta et al., 2000). Due to these functional differences, INs display class-specific roles in regulating network excitability via mechanisms such as spike timing control and modulation of synaptic integration (Pinto et al., 2000; Pouille and Scanziani, 2001; Wehr and Zador, 2003; Gabernet et al., 2005). Cortical output via PNs 

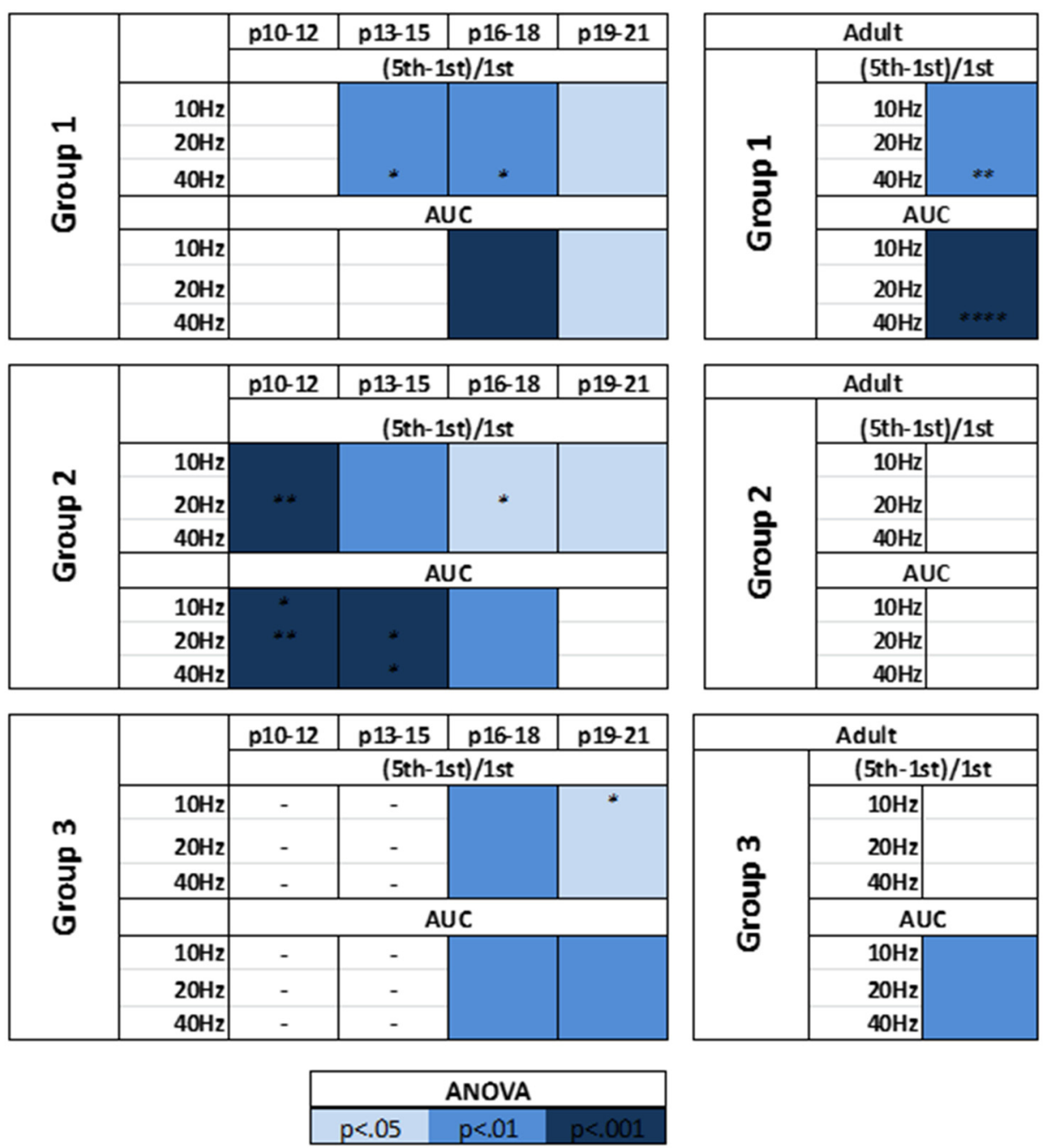

FIGURE 10 | HCN channels display distinct patterns of synaptic excitability modulation in identified L1 IN groups throughout development. A summary of the effects of HCN channels blockade on the synaptic excitability of identified cell groups throughout development. Viewing developmental data together with data generated from adult cells, clear developmental patterns of HCN channel modulation emerge, with modulation increasing and decreasing with age in RS and NA cells, respectively. Statistical comparison was performed on values obtained before and after ZD7288 wash-on. ${ }^{*} p<0.05$, ${ }^{* *} p<0.01$, ${ }^{* * * *} p<0.0001$, Dunn-Sidak's post-test.

is strongly directed by the integration of synaptic inputs to PN dendrites. The ability of synaptic inputs to affect PN firing requires spatiotemporal integration of multiple signals in order to facilitate EPSP summation and propagation to the soma (Magee, 2000). This synaptic summation involves the additive effect of synchronous EPSPs, as well as the divisive integration of inhibitory, GABAergic input (Palmer et al., 2012b; Chiu et al., 2013; Lee et al., 2014). As such, the relative timing and kinetics of inhibitory and excitatory inputs directly affect PC firing and synaptic plasticity (Golding et al., 2002; Larkum et al., 2009).

HCN channels have been shown to modulate the excitability of CR cells (Kilb and Luhmann, 2000) and affect the intrinsic and synaptic excitability of diverse cortical INs (Albertson et al., 2011, 2017). HCN channels can be active at rest, contributing to the RMP and conductance of the membrane in a cell-type specific manner (Pape, 1996; Lupica et al., 2001; Nolan et al., 2003; Day et al., 2005; Meuth et al., 2006). Although not a canonically associated function, HCN channels can also modulate repetitive firing properties via attenuation of AP half-width and mAHP duration (Tanaka et al., 2003; Kouranova et al., 2008; Cho et al., 2011). Of note, current methods have not been able to elucidate the subcellular localization of HCN channels which strongly determines their contribution to neuronal activity and excitability. As with PNs, spatiotemporal integration of multiple signals is necessary for synaptic inputs to modify the firing patterns of INs. Many studies have characterized a role for $\mathrm{HCN}$ channels in restricting the spatiotemporal integration of synaptic inputs (Stuart and Spruston, 1998; Williams and Stuart, 2000; Berger et al., 2001; Albertson et al., 2011). Specifically, HCN channels have been 

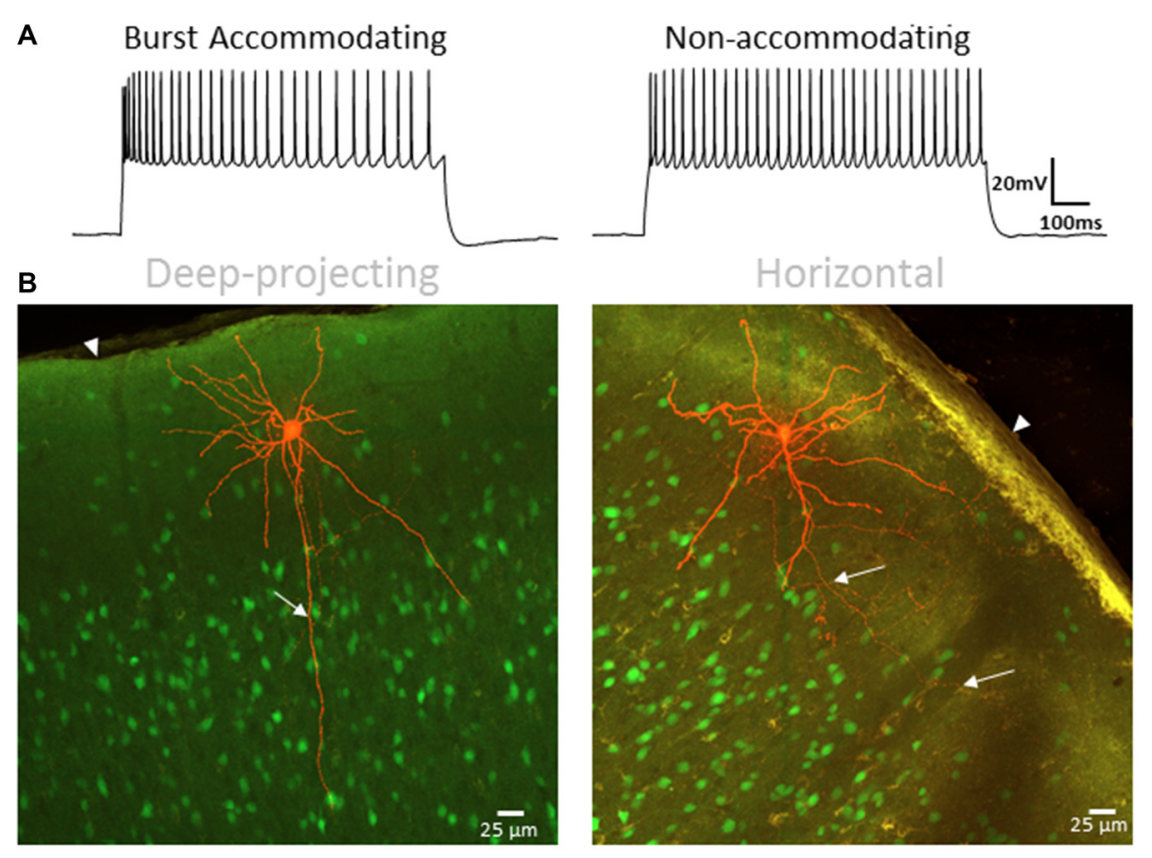

FIGURE 11 | L1 IN physiology correlates with morphology. (A) Specimen records showing BA (left) and NA (right) firing patterns used for correlation with axonal projection type. (B) Representative images of a deep-projecting (left) and horizontally-confined (right) L1 INs. Labeled cells are shown in red with other VGAT-positive cells shown in green. White arrows indicate axonal projections whereas arrowheads indicate the pial surface. A significant correlation between type of axon projection and physiology was identified $\left(\chi^{2}: p<0.01\right)$, with a distinct deep projecting axon being identified in a larger percentage of BA cells (BA = 11 of 14 , $N A=1$ of 8$)$, while a greater portion of NA cells were identified as horizontally projecting $(B A=1$ of $14, N A=3$ of 8$)$. Scale bar $=25 \mu \mathrm{m}$.

shown to attenuate the amplitude and duration of EPSPs, and act as a coincidence detector by preferentially facilitating the summation of spatially distributed inputs which arrive within a narrow temporal window (Dembrow et al., 2015). HCN channels can therefore act as key modulators of neuronal firing in response to synaptic input through effects on both intrinsic and synaptic neuronal excitability. HCN modulatory effects in L1 INs could subsequently influence the integration of synaptic inputs on PC dendrites, potentially altering cortical output.

In addition to the sparse IN population, $\mathrm{L} 1$ also contains dense axonal and dendritic plexuses. PNs in cortical layers $2 / 3,5$ and 6 are the sole output neurons of the cortex, and are characterized by their long, apical dendrites which ramify extensively in superficial layers, particularly L1 (Gottlieb and Keller, 1997; Larsen and Callaway, 2006; Oberlaender et al., 2011). Inputs from multiple pathways converge onto the dendritic trees of PNs in L1 (Vogt, 1991; Mitchell and Cauller, 2001; Llinás et al., 2002; Arroyo et al., 2012; Cruikshank et al., 2012). L1 INs are also targeted by these inputs and are uniquely positioned to directly inhibit the apical tufts of pyramidal cells (Hestrin and Armstrong, 1996; Zhou and Hablitz, 1996a; Larkum and Zhu, 2002; Zhu and Zhu, 2004), which are critical for the spatiotemporal integration of their multiple inputs (Vogt, 1991; Williams, 2004; Larkum et al., 2009; Palmer et al., 2012a). As such, the intrinsic excitability and synaptic integration properties of L1 cell populations are pivotal in maintaining the network dynamics underlying cortical information processing.
Given that inputs to $\mathrm{L} 1$ potentially form synapses on both $\mathrm{PN}$ dendrites and $\mathrm{L} 1 \mathrm{INs}, \mathrm{PN}$ dendrites can receive a combination of excitatory input and feedforward inhibition from activation of a single afferent fiber (Mitchell and Cauller, 2001; Llinás et al., 2002; Larkum et al., 2009). Following classical Hebbian plasticity, synaptic connectivity is strongly modified by changes in the input-output dynamics of synaptically coupled cells. Early in development, the correlation between a synaptic input and the firing of the post-synaptic cell will influence the strengthening or pruning of that synapse (Purves and Lichtman, 1980; Shatz, 1990; Katz and Shatz, 1996). The excitability of L1 INs is central to determination of the timing and kinetics of their synaptic output, which modulates the integration of spatiotemporally distinct inputs on PN dendrites. In this way, the excitability of L1 INs during development can affect the formation of cortical connectivity patterns which produce information circuits that will persist into maturity.

\section{Different Contributions of IN Subtypes to Cortical Network Activity}

The L1 IN subtypes we have identified coincide well with other reported classification dichotomies: deep projecting, accommodating cells have been identified as elongated neurogliaform cells (ENGCs) and horizontal, NA cells as single-bouquet cells (SBCs; Kubota et al., 2011; Jiang et al., 2013). These studies have characterized these L1 IN subtypes, 
identifying distinct patterns of synaptic connectivity. Of particular relevance to our findings, opposing effects on PC firing have been reported for these identified cell types (Larkum, 2013). Specifically, Jiang et al. (2013) found that activation of SBCs resulted in an increase in PC firing through disinhibition of L2/3 INs, whereas NGC activation produced a significant decrease in PC firing via synchronization of L2/3 IN firing which resulted in a decrease of dendritic spikes.

Our recent work has shown that in addition to regulating the intrinsic excitability of PCs and excitatory network activity, HCN channels also constrain GABAergic network activity (Williams and Hablitz, 2015). The conflicting effect of SBCs and NGCs on PC firing could be of particular importance when establishing synaptic connectivity patterns during cortical development. The differential patterns of HCN channel effects could facilitate complementary roles for the two IN classes. HCN channel-mediated attenuation of NGC/NA cells' synaptic excitability early in development would restrict temporal EPSP summation in those cells. In theory, this effect would attenuate the summation of temporally separate inputs and decrease the probability of AP elicitation, thereby preventing the correlation of distinct afferents and possibly prompting the pruning of those synapses. Conversely, spatially disparate, yet synchronous inputs to NA neurons would have an increased probability of eliciting an AP under these conditions, subsequently producing an increase in $\mathrm{PC}$ firing through inhibition of L2/3 INs. By providing synchronous input to NA cells, distinct afferents could become correlated through synaptic strengthening as a result of direct correlation to the firing of both NA cells and PCs. Through this mechanism, synaptic connectivity and correlation patterns could be established which would be stabilized by the formation of perineuronal nets throughout development. With maturity and stabilization of synaptic connectivity and synchronicity, the specificity of synaptic integration conferred by HCN channels would be of less importance than during development. Furthermore, the lack of HCN channel-mediated EPSP attenuation in adults would increase the probability of synaptic input triggering an AP.

In RS cells, the lack of HCN channel modulation early in development would enhance the probability of AP firing in response to synaptic input. Under these conditions, synaptic input causing activation of a RS cell would produce a decrease in PC firing through synchronization of L2/3 mediated

\section{REFERENCES}

Albertson, A. J., Bohannon, A. S., and Hablitz, J. J. (2017). HCN channel modulation of synaptic integration in GABAergic interneurons in malformed rat neocortex. Front. Cell. Neurosci. 11:109. doi: 10.3389/fncel.2017. 00109

Albertson, A. J., Williams, S. B., and Hablitz, J. J. (2013). Regulation of epileptiform discharges in rat neocortex by HCN channels. J. Neurophysiol. 110, 1733-1743. doi: 10.1152/jn.00955.2012

Albertson, A. J., Yang, J., and Hablitz, J. J. (2011). Decreased hyperpolarizationactivated currents in layer 5 pyramidal neurons enhances excitability in focal cortical dysplasia. J. Neurophysiol. 106, 2189-2200. doi: 10.1152/jn.00 164.2011 inhibition. With increased HCN channel modulation in adults, the summation of synaptic inputs onto RS cells would be attenuated, thereby decreasing the probability of eliciting an $\mathrm{AP}$ in a RS cell and consequently decreasing inhibition of PC firing. In theory, the inverse developmental patterns of $\mathrm{HCN}$ channel effects in NA and RS cells convey synaptic dynamics which are complementary in terms of network dynamics. As a consequence of HCN channel function early in development, temporally disparate synaptic inputs to L1 INs are likely to exert only a small influence on PC firing, preferentially causing a decrease in firing rate. Synchronous input to L1 during this time, however, would likely cause a significant increase in PC firing due to the modulatory effect of $\mathrm{HCN}$ channels on NA cells' synaptic integration. Theoretically, the opposite would then hold true under the conditions of altered HCN channel modulatory effects in adults. It is likely that asynchronous input to L1 in the mature cortex would still induce only a modest change in PC firing; however the effect would more likely be an increase in PC firing. Conversely, due to the effects of HCN channels on RS cells' synaptic integration, synchronous input to L1 would more likely increase PC firing early in development. In this way, HCN channels could potentially serve to refine synaptic connectivity and dynamics during development and constrain the excitability of the mature cortex. Further experiments are necessary to directly test this paradigm, as this study has not investigated how the modulatory effects of HCN channels on L1 INs affects PC firing or di-synaptic inputs to PCs. Given that electrical coupling has been observed between L1 INs (Muralidhar et al., 2014; Yao et al., 2016), further studies are also necessary to determine if intergroup coupling exists or if coupling is exclusively between physiologically similar cells, creating isolated synchronized networks.

\section{AUTHOR CONTRIBUTIONS}

ASB and JJH designed the research and wrote the manuscript. ASB conducted experiments and analyzed the data.

\section{FUNDING}

This work was supported by National Institute of Neurological Disorders and Stroke, National Institutes of Health grants NS090041 and P30 NS047466.

Aponte, Y., Lien, C. C., Reisinger, E., and Jonas, P. (2006). Hyperpolarizationactivated cation channels in fast-spiking interneurons of rat hippocampus. J. Physiol. 574, 229-243. doi: 10.1113/jphysiol.2005.104042

Arroyo, S., Bennett, C., Aziz, D., Brown, S. P., and Hestrin, S. (2012). Prolonged disynaptic inhibition in the cortex mediated by slow, non- $\alpha 7$ nicotinic excitation of a specific subset of cortical interneurons. J. Neurosci. 32, 3859-3864. doi: 10.1523/JNEUROSCI.0115-12.2012

Baruscotti, M., Bottelli, G., Milanesi, R., DiFrancesco, J. C., and DiFrancesco, D. (2010). HCN-related channelopathies. Pflugers Arch. 460, 405-415. doi: 10.1007/s00424-010-0810-8

Bender, R. A., and Baram, T. Z. (2008). Hyperpolarization activated cyclicnucleotide gated (HCN) channels in developing neuronal networks. Prog. Neurobiol. 86, 129-140. doi: 10.1016/j.pneurobio.2008.09.007 
Berger, T., Larkum, M. E., and Lüscher, H.-R. (2001). High $I_{\mathrm{h}}$ channel density in the distal apical dendrite of layer $\mathrm{V}$ pyramidal cells increases bidirectional attenuation of EPSPs. J. Neurophysiol. 85, 855-868. doi: 10.1152/jn.2001.85. 2.855

Biel, M., Wahl-Schott, C., Michalakis, S., and Zong, X. (2009). Hyperpolarizationactivated cation channels: from genes to function. Physiol. Rev. 89, 847-885. doi: 10.1152/physrev.00029.2008

Bradford, R., Parnavelas, J. G., and Lieberman, A. R. (1978). Neurons in layer I of the developing occipital cortex of the rat. J. Comp. Neurol. 176, 121-132. doi: $10.1002 /$ cne. 901760108

Cauli, B., Audinat, E., Lambolez, B., Angulo, M. C., Ropert, N., Tsuzuki, K., et al. (1997). Molecular and physiological diversity of cortical nonpyramidal cells. J. Neurosci. 17, 3894-3906.

Cauller, L. J. (1995). Layer I of primary sensory neocortex: where top-down converges upon bottom-up. Behav. Brain Res. 71, 163-170. doi: 10.1016/01664328(95)00032-1

Cauller, L. J., Clancy, B., and Connors, B. W. (1998). Backward cortical projections to primary somatosensory cortex in rats extend long horizontal axons in layer I. J. Comp. Neurol. 390, 297-310. doi: 10.1002/(sici)10969861(19980112)390:2<297::aid-cne11>3.0.co;2-v

Chiu, C. Q., Lur, G., Morse, T. M., Carnevale, N. T., Ellis-Davies, G. C., and Higley, M. J. (2013). Compartmentalization of GABAergic inhibition by dendritic spines. Science 10, 759-762. doi: 10.1126/science. 1234274

Cho, H., Furness, J. B., and Jennings, E. A. (2011). Postnatal maturation of the hyperpolarization-activated cation current, $I_{\mathrm{h}}$, in trigeminal sensory neurons. J. Neurophysiol. 106, 2045-2056. doi: 10.1152/jn.00798.2010

Chowdhury, T., Jimenez, J., Bomar, J., Cruz-Martin, A., Cantle, J., and Portera-Cailliau, C. (2010). Fate of Cajal-Retzius neurons in the postnatal mouse neocortex. Front. Neuroanatomy. 4:10. doi: 10.3389/neuro.05. 010.2010

Chu, Z., Galarreta, M., and Hestrin, S. (2003). Synaptic interactions of late-spiking neocortical neurons in layer 1. J. Neurosci. 23, 96-102.

Chun, J. J., and Shatz, C. J. (1989). The earliest-generated neurons of the cat cerebral cortex: characterization by MAP2 and neurotransmitter immunohistochemistry during fetal life. J. Neurosci. 9, 1648-1667.

Cobos, I., Calcagnotto, M. E., Vilaythong, A. J., Thwin, M. T., Noebels, J. L., Baraban, S. C., et al. (2005). Mice lacking Dlx1 show subtype-specific loss of interneurons, reduced inhibition and epilepsy. Nat. Neurosci. 8, 1059-1068. doi: $10.1038 / \mathrm{nn} 1499$

Cossart, R., Dinocourt, C., Hirsch, J. C., Merchan-Perez, A., De Felipe, J., Ben-Ari, Y., et al. (2001). Dendritic but not somatic GABAergic inhibition is decreased in experimental epilepsy. Nat. Neurosci. 4, 52-62. doi: 10.1038/ 82900

Cruikshank, S. J., Ahmed, O. J., Stevens, T. R., Patrick, S. L., Gonzalez, A. N., Elmaleh, M., et al. (2012). Thalamic control of layer 1 circuits in prefrontal cortex. J. Neurosci. 32, 17813-17823. doi: 10.1523/JNEUROSCI.3231 $-12.2012$

Cuttle, M. F., Rusznák, Z., Wong, A. Y. C., Owens, S., and Forsythe, I. D. (2001). Modulation of a presynaptic hyperpolarization-activated cationic current $I_{\mathrm{h}}$ at an excitatory synaptic terminal in the rat auditory brainstem. J. Physiol. 534, 733-744. doi: 10.1111/j.1469-7793.2001.00733.x

Day, M., Carr, D. B., Ulrich, S., Ilijic, E., Tkatch, T., and Surmeier, D. J. (2005). Dendritic excitability of mouse frontal cortex pyramidal neurons is shaped by the interaction among HCN, Kir2, and Kleak channels. J. Neurosci. 25, 8776-8787. doi: 10.1523/JNEUROSCI.2650-05.2005

DeFelipe, J. (1993). Neocortical neuronal diversity: chemical heterogeneity revealed by colocalization studies of classic neurotransmitters, neuropeptides, calcium-binding proteins, and cell surface molecules. Cereb. Cortex 3, 273-289. doi: $10.1093 /$ cercor/3.4.273

DeFelipe, J., and Jones, E. J. (1988). Cajal on the Cerebral Cortex. New York, NY: Oxford University Press.

del Río, J. A., Martínez, A., Fonseca, M., Auladell, C., and Soriano, E. (1995). Glutamate-like immunoreactivity and fate of Cajal-Retzius cells in the murine cortex as identified with calretinin antibody. Cereb. Cortex 5, 13-21. doi: $10.1093 /$ cercor/5.1.13

Dembrow, N. C., Zemelman, B. V., and Johnston, D. (2015). Temporal dynamics of L5 dendrites in medial prefrontal cortex regulate integration versus coincidence detection of afferent inputs. J. Neurosci. 35, 4501-4514. doi: 10.1523/JNEUROSCI.4673-14.2015

Donoghue, J. P., and Wise, S. P. (1982). The motor cortex of the rat: cytoarchitecture and microstimulation mapping. J. Comp. Neurol. 212, 76-88. doi: $10.1002 / \mathrm{cne} .902120106$

Dyhrfjeld-Johnsen, J., Morgan, R., and Soltesz, I. (2009). Double trouble? Potential for hyperexcitability following both channelopathic up- and downregulation of $I_{\mathrm{h}}$ in epilepsy. Front. Neurosci. 3, 25-33. doi: 10.3389/neuro.01. 005.2009

Erlich, J. C., Bialek, M., and Brody, C. D. (2011). A cortical substrate for memoryguided orienting in the rat. Neuron 72, 330-343. doi: 10.1016/j.neuron.2011. 07.010

Gabernet, L., Jadhav, S. P., Feldman, D. E., Carandini, M., and Scanziani, M. (2005). Somatosensory integration controlled by dynamic thalamocortical feed-forward inhibition. Neuron 48, 315-327. doi: 10.1016/j.neuron.2005. 09.022

Golding, N. L., Staff, N. P., and Spruston, N. (2002). Dendritic spikes as a mechanism for cooperative long-term potentiation. Nature 418, 326-331. doi: $10.1038 /$ nature 00854

Gottlieb, J. P., and Keller, A. (1997). Intrinsic circuitry and physiological properties of pyramidal neurons in rat barrel cortex. Exp. Brain Res. 115, 47-60. doi: $10.1007 / \mathrm{pl} 00005684$

Gu, X., Staines, W. A., and Fortier, P. A. (1999). Quantitative analyses of neurons projecting to primary motor cortex zones controlling limb movements in the rat. Brain Res. 835, 175-187. doi: 10.1016/s0006-8993(99)01576-0

Gupta, A., Wang, Y., and Markram, H. (2000). Organizing principles for a diversity of GABAergic interneurons and synapses in the neocortex. Science 287, 273-278. doi: 10.1126/science.287.5451.273

Hestrin, S., and Armstrong, W. E. (1996). Morphology and physiology of cortical neurons in layer I. J. Neurosci. 16, 5290-5300.

$\mathrm{Hu}, \mathrm{H}$., Gan, J., and Jonas, P. (2014). Fast-spiking, parvalbumin ${ }^{+}$GABAergic interneurons: from cellular design to microcircuit function. Science 345:1255263. doi: 10.1126/science. 1255263

Huang, Z., Walker, M. C., and Shah, M. M. (2009). Loss of dendritic HCN1 subunits enhances cortical excitability and epileptogenesis. J. Neurosci. 29, 10979-10988. doi: 10.1523/JNEUROSCI.1531-09.2009

Jeong, M., Kim, Y., Kim, J., Ferrante, D. D., Mitra, P. P., Osten, P., et al. (2016). Comparative three-dimensional connectome map of motor cortical projections in the mouse brain. Sci. Rep. 6:20072. doi: 10.1038/srep20072

Jiang, X., Wang, G., Lee, A. J., Stornetta, R. L., and Zhu, J. J. (2013). The organization of two new cortical interneuronal circuits. Nat. Neurosci. 16, 210-218. doi: 10.1038/nn.3305

Kargo, W. J., Szatmary, B., and Nitz, D. A. (2007). Adaptation of prefrontal cortical firing patterns and their fidelity to changes in action-reward contingencies. J. Neurosci. 27, 3548-3559. doi: 10.1523/JNEUROSCI.3604 $-06.2007$

Katz, L. C., and Shatz, C. J. (1996). Synaptic activity and the construction of cortical circuits. Science 274, 1133-1138. doi: 10.1126/science.274.5290.1133

Kawaguchi, Y., and Kubota, Y. (1997). GABAergic cell subtypes and their synaptic connections in rat frontal cortex. Cereb. Cortex 7, 476-486. doi: $10.1093 /$ cercor/7.6.476

Kilb, W., and Luhmann, H. J. (2000). Characterization of a hyperpolarizationactivated inward current in Cajal-Retzius cells in rat neonatal neocortex. J. Neurophysiol. 84, 1681-1691. doi: 10.1152/jn.2000.84.3.1681

Kirischuk, S., Luhmann, H. J., and Kilb, W. (2014). Cajal-Retzius cells: update on structural and functional properties of these mystic neurons that bridged the 20th century. Neuroscience 275, 33-46. doi: 10.1016/j.neuroscience.2014. 06.009

Kouranova, E. V., Strassle, B. W., Ring, R. H., Bowlby, M. R., and Vasilyev, D. V. (2008). Hyperpolarization-activated cyclic nucleotide-gated channel mRNA and protein expression in large versus small diameter dorsal root ganglion neurons: correlation with hyperpolarization-activated current gating. Neuroscience 153, 1008-1019. doi: 10.1016/j.neuroscience.2008. 03.032

Kubota, Y., Shigematsu, N., Karube, F., Sekigawa, A., Kato, S., Yamaguchi, N., et al. (2011). Selective coexpression of multiple chemical markers defines discrete populations of neocortical GABAergic neurons. Cereb. Cortex 21, 1803-1817. doi: 10.1093/cercor/bhq252 
Larkum, M. E. (2013). The yin and yang of cortical layer 1. Nat. Neurosci. 16, 114-115. doi: 10.1038/nn.3317

Larkum, M. E., Nevian, T., Sandler, M., Polsky, A., and Schiller, J. (2009). Synaptic integration in tuft dendrites of layer 5 pyramidal neurons: A new unifying principle. Science $325,756-760$. doi: 10.1126/science. 1171958

Larkum, M. E., and Zhu, J. J. (2002). Signaling of layer 1 and whisker-evoked $\mathrm{Ca}^{2+}$ and $\mathrm{Na}^{+}$action potentials in distal and terminal dendrites of rat neocortical pyramidal neurons in vitro and in vivo. J. Neurosci. 22, 6991-7005.

Larsen, D. D., and Callaway, E. M. (2006). Development of layer-specific axonal arborizations in mouse primary somatosensory cortex. J. Comp. Neurol. 494, 398-414. doi: 10.1002/cne.20754

Lee, A., Gee, S., Vogt, D., Patel, T., Rubenstein, J., and Sohal, V. (2014). Pyramidal neurons in prefrontal cortex receive subtype-specific forms of excitation and inhibition. Neuron 81, 61-68. doi: 10.1016/j.neuron.2013. 10.031

Lee, A. J., Wang, G., Jiang, X., Johnson, S. M., Hoang, E. T., Lanté, F., et al. (2015). Canonical organization of layer 1 neuron-led cortical inhibitory and disinhibitory interneuronal circuits. Cereb. Cortex 25, 2114-2126. doi: 10.1093/cercor/bhu020

Li, N., Chen, T. W., Guo, Z. V., Gerfen, C. R., and Svoboda, K. (2015). A motor cortex circuit for motor planning and movement. Nature 519, 51-56. doi: $10.1038 /$ nature 14178

Llinás, R. R., Leznik, E., and Urbano, F. J. (2002). Temporal binding via cortical coincidence detection of specific and nonspecific thalamocortical inputs: a voltage-dependent dye-imaging study in mouse brain slices. Proc. Natl. Acad. Sci. U S A 99, 449-454. doi: 10.1073/pnas.012604899

Ludwig, A., Budde, T., Stieber, J., Moosmang, S., Wahl, C., Holthoff, K., et al. (2003). Absence epilepsy and sinus dysrhythmia in mice lacking the pacemaker channel HCN2. EMBO J. 22, 216-224. doi: 10.1093/emboj/cdg032

Lupica, C. R., Bell, J. A., Hoffman, A. F., and Watson, P. L. (2001). Contribution of the hyperpolarization-activated current $I_{\mathrm{h}}$ to membrane potential and GABA release in hippocampal interneurons. J. Neurophysiol. 86, 261-268. doi: 10.1152/jn.2001.86.1.261

Ma, J., Yao, X. H., Fu, Y., and Yu, Y. C. (2014). Development of layer 1 neurons in the mouse neocortex. Cereb. Cortex 24, 2604-2618. doi: 10.1093/cercor/bht114

Magee, J. C. (2000). Dendritic integration of excitatory synaptic input. Nat. Rev. Neurosci. 1, 181-190. doi: 10.1038/35044552

Markram, H., Toledo-Rodriguez, M., Wang, Y., Gupta, A., Silberberg, G., and $\mathrm{Wu}, \mathrm{C}$. (2004). Interneurons of the neocortical inhibitory system. Nat. Rev. Neurosci. 5, 793-807. doi: 10.1038/nrn1519

Meuth, S. G., Kanyshkova, T., Meuth, P., Landgraf, P., Munsch, T., Ludwig, A., et al. (2006). Membrane resting potential of thalamocortical relay neurons is shaped by the interaction among TASK3 and HCN2 channels. J. Neurophysiol. 96, 1517-1529. doi: 10.1152/jn.01212.2005

Mitchell, B. D., and Cauller, L. J. (2001). Corticocortical and thalamocortical projections to layer I of the frontal neocortex in rats. Brain Res. 921, 68-77. doi: 10.1016/s0006-8993(01)03084-0

Murakami, M., Vincent, M. I., Costa, G. M., and Mainen, Z. F. (2014). Neural antecedents of self-initiated actions in secondary motor cortex. Nat. Neurosci. 17, 1574-1582. doi: 10.1038/nn.3826

Muralidhar, S., Wang, Y., and Markram, H. (2014). Synaptic and cellular organization of layer 1 of the developing rat somatosensory cortex. Front. Neuroanat. 7:52. doi: 10.3389/fnana.2013.00052

Neafsey, E. J., Bold, E. L., Haas, G., Hurley-Gius, K. M., Quirk, G., Sievert, C. F., et al. (1986). The organization of the rat motor cortex: a microstimulation mapping study. Brain Res. 396, 77-96. doi: 10.1016/s0006-8993(86) 80191-3

Nolan, M. F., Malleret, G., Lee, K. H., Gibbs, E., Dudman, J. T., Santoro, B., et al. (2003). The hyperpolarization-activated HCN1 channel is important for motor learning and neuronal integration by cerebellar purkinje cells. Cell 115, 551-564. doi: 10.1016/s0092-8674(03)00884-5

Oberlaender, M., Boudewijns, Z. S. R. M., Kleele, T., Mansvelder, H. D., Sakmann, B., and de Kock, C. P. J. (2011). Three-dimensional axon morphologies of individual layer 5 neurons indicate cell type-specific intracortical pathways for whisker motion and touch. Proc. Natl. Acad. Sci. U S A 108, 4188-4193. doi: 10.1073/pnas.1100647108

Ogawa, M., Miyata, T., Kakajimat, K., Yagyu, K., Seike, M., Ikenaka, K., et al. (1995). The reeler gene-associated antigen on Cajal-Retzius neurons is a crucial molecule for laminar organization of cortical neurons. Neuron 14, 899-912. doi: 10.1016/0896-6273(95)90329-1

Ostlund, S. B., Winterbauer, N. E., and Balleine, B. W. (2009). Evidence of action sequence chunking in goal-directed instrumental conditioning and its dependence on the dorsomedial prefrontal cortex. J. Neurosci. 29, 8280-8287. doi: 10.1523/JNEUROSCI.1176-09.2009

Palmer, L. M., Murayama, M., and Larkum, M. E. (2012a). Inhibitory regulation of dendritic activity in vivo. Front. Neural Circuits 6:26. doi: 10.3389/fncir.2012 00026

Palmer, L. M., Schulz, J. M., Murphy, S. C., Ledergerber, D., Murayama, M., and Larkum, M. E. (2012b). The cellular basis of GABAB-mediated interhemispheric inhibition. Science 335, 989-993. doi: 10.1126/science. 1217276

Pape, H. C. (1996). Queer current and pacemaker: the hyperpolarizationactivated cation current in neurons. Annu. Rev. Physiol. 58, 299-327. doi: 10.1146/annurev.physiol.58.1.299

Passingham, R. E., Myers, C., Rawlins, N., Lightfoot, V., and Fearn, S. (1988). Premotor cortex in the rat. Behav. Neurosci. 102, 101-109. doi: 10.1037/07357044.102.1.101

Peters, A., and Jones, E. G. (1984). Cellular Components of the Cerebral Cortex. New York, NY: Plenum Press.

Petreanu, L., Mao, T., Sternson, S. M., and Svoboda, K. (2009). The subcellular organization of neocortical excitatory connections. Nature 457, 1142-1145. doi: 10.1038/nature07709

Pfeffer, C. K., Xue, M., He, M., Huang, Z. J., and Scanziani, M. (2013). Inhibition of inhibition in visual cortex: the logic of connections between molecularly distinct interneurons. Nat. Neurosci. 16, 1068-1076. doi: 10.1038/ nn.3446

Pinto, D. J., Brumberg, J. C., and Simons, D. J. (2000). Circuit dynamics and coding strategies in rodent somatosensory cortex. J. Neurophysiol. 83, 1158-1166. doi: $10.1152 /$ jn.2000.83.3.1158

Pouille, F., and Scanziani, M. (2001). Enforcement of temporal fidelity in pyramidal cells by somatic feed-forward inhibition. Science 293, 1159-1163. doi: 10.1126/science.1060342

Purves, D., and Lichtman, J. W. (1980). Elimination of synapses in the developing nervous system. Science 210, 153-157. doi: 10.1126/science.7414326

Reep, R. L., Corwin, J. V., Hashimoto, A., and Watson, R. T. (1987). Efferent connections of the rostral portion of medial agranular cortex in rats. Brain Res. Bull. 19, 203-221. doi: 10.1016/0361-9230(87)90086-4

Reep, R. L., Goodwin, G. S., and Corwin, J. V. (1990). Topographic organization in the corticocortical connections of medial agranular cortex in rats. J. Comp. Neurol. 294, 262-280. doi: 10.1002/cne.902940210

Reid, C. A., Phillips, A. M., and Petrou, S. (2012). HCN channelopathies: pathophysiology in genetic epilepsy and therapeutic implications. $\mathrm{Br}$. J. Pharmacol. 165, 49-56. doi: 10.1111/j.1476-5381.2011.01507.x

Robinson, R. B., and Siegelbaum, S. A. (2003). Hyperpolarization-activated cation currents: from molecules to physiological function. Annu. Rev. Physiol. 65, 453-480. doi: 10.1146/annurev.physiol.65.092101.142734

Rubio-Garrido, P., Pérez-de-Manzo, F., Porrero, C., Galazo, M. J., and Clascá, F. (2009). Thalamic input to distal apical dendrites in neocortical layer 1 is massive and highly convergent. Cereb. Cortex 19, 2380-2395. doi: $10.1093 /$ cercor/bhn259

Sanderson, K. J., Welker, W., and Shambes, G. M. (1984). Reevaluation of motor cortex and of sensorimotor overlap in cerebral cortex of albino rats. Brain Res. 292, 251-260. doi: 10.1016/0006-8993(84)90761-3

Santoro, B., Grant, S. G. N., Bartsch, D., and Kandel, E. R. (1997). Interactive cloning with the SH3 domain of $\mathrm{N}$-src identifies a new brain specific ion channel protein, with homology to Eag and cyclic nucleotide-gated channels. Proc. Natl. Acad. Sci. U S A 94, 14815-14820. doi: 10.1073/pnas.94.26. 14815

Santoro, B., Lee, K., Englot, D. J., Gildersleeve, S., Piskorowski, R. A., Siegelbaum, S. A., et al. (2010). Increased seizure severity and seizure-related death in mice lacking HCN I channels. Epilepsia 51, 1624-1627. doi: 10.1111/j. 1528-1167.2010.02554.x

Seo, H., Seol, M.-J., and Lee, K. (2015). Differential expression of hyperpolarization-activated cyclic nucleotide-gated channel subunits during hippocampal development in the mouse. Mol. Brain 8:13. doi: 10.1186/s13041015-0103-4 
Shah, M. M., Huang, Z., and Martinello, K. (2012). HCN and KV7 (M-) channels as targets for epilepsy treatment. Neuropharmacology 69, 75-81. doi: 10.1016/j. neuropharm.2012.03.005

Shatz, C. J. (1990). Impulse activity and the patterning of connections during CNS developmerit. Neuron 5, 745-756. doi: 10.1016/0896-6273(90)90333-b

Silberberg, G. (2008). Polysynaptic subcircuits in the neocortex: spatial and temporal diversity. Curr. Opin. Neurobiol. 18, 332-337. doi: 10.1016/j.conb. 2008.08.009

Shlosberg, D., Amitai, Y., and Azouz, R. (2006). Time-dependent, layerspecific modulation of sensory responses mediated by neocortical layer 1 . J. Neurophysiol. 96, 3170-3182. doi: 10.1152/jn.00520.2006

Soda, T., Nakashima, R., Watanabe, D., Nakajima, K., Pastan, I., and Nakanishi, S. (2003). Segregation and coactivation of developing neocortical layer 1 neurons. J. Neurosci. 23, 6272-6279.

Southan, A. P., Morris, N. P., Stephens, G. J., and Robertson, B. (2000). Hyperpolarization-activated currents in presynaptic terminals of mouse cerebellar basket cells. J. Physiol. 526, 91-97. doi: 10.1111/j.1469-7793.2000.t011-00091.x

Stuart, G., and Spruston, N. (1998). Determinants of voltage attenuation in neocortical pyramidal neuron dendrites. J. Neurosci. 18, 3501-3510.

Sul, J. H., Jo, S., Lee, D., and Jung, M. W. (2011). Role of rodent secondary motor cortex in value-based action selection. Nat. Neurosci. 14, 1202-1208. doi: 10.1038/nn.2881

Surges, R., Brewster, A., Bender, R. A., Beck, H., Feuerstein, T. J., and Baram, T. Z. (2006). Regulated expression of HCN channels and cAMP levels shape the properties of the h current in developing rat hippocampus. Eur. J. Neurosci. 24, 94-104. doi: 10.1111/j.1460-9568.2006.04880.x

Tanaka, Y., Tanaka, Y., Furuta, T., Yanagawa, Y., and Kaneko, T. (2008). The effects of cutting solutions on the viability of GABAergic interneurons in cerebral cortical slices of adult mice. J. Neurosci. Methods 171, 118-125. doi: 10.1016/j.jneumeth.2008.02.021

Tanaka, S., Wu, N., Hsaio, C.-F., Turman, J. Jr., and Chandler, S. H. (2003). Development of inward rectification and control of membrane excitability in mesencephalic V neurons. J. Neurophysiol. 89, 1288-1298. doi: 10.1152/jn. 00850.2002

Trevelyan, A. J., Sussillo, D., Watson, B. O., and Yuste, R. (2006). Modular propagation of epileptiform activity: evidence for an inhibitory veto in neocortex. J. Neurosci. 26, 12447-12455. doi: 10.1523/JNEUROSCI.278706.2006

Uematsu, M., Hirai, Y., Karube, F., Ebihara, S., Kato, M., Abe, K., et al. (2008). Quantitative chemical composition of cortical GABAergic neurons revealed in transgenic venus-expressing rats. Cereb. Cortex 18, 315-330. doi: 10.1093/cercor/bhm056

Vogt, B. A. (1991). "The role of layer I in cortical function," in Cerebral Cortex, Volume 9: Normal and Altered States of Function, eds A. Peter and E. G. Jones (New York, NY: Plenum Press), 49-80.

Wehr, M., and Zador, A. M. (2003). Balanced inhibition underlies tuning and sharpens spike timing in auditory cortex. Nature 426, 442-446. doi: $10.1038 /$ nature 02116

Wessa, P. (2012). Hierarchical Clustering (v1.0.3) in Free Statistics Software $(v 1.1 .23-r 7)$. Office for Research Development and Education. Available online at: http://www.wessa.net/rwasp_hierarchicalclustering.wasp/
Williams, S. R. (2004). Spatial compartmentalization and functional impact of conductance in pyramidal neurons. Nat. Neurosci. 7, 961-967. doi: $10.1038 / \mathrm{nn} 1305$

Williams, S. B., and Hablitz, J. J. (2015). Differential modulation of repetitive firing and synchronous network activity in neocortical interneurons by inhibition of A-type $\mathrm{K}^{+}$channels and $I_{\mathrm{h}}$. Front. Cell. Neurosci. 9:89. doi: 10.3389/fncel.2015. 00089

Williams, S. R., and Stuart, G. J. (2000). Site independence of EPSP time course is mediated by dendritic $I_{\mathrm{h}}$ in neocortical pyramidal neurons. J. Neurophysiol. 83, 3177-3182. doi: 10.1152/jn.2000.83.5.3177

Winer, J. A., and Larue, D. T. (1989). Populations of GABAergic neurons and axons in layer I of rat auditory cortex. Neuroscience 33, 499-515. doi: 10.1016/0306-4522(89)90402-8

Wozny, C., and Williams, S. R. (2011). Specificity of synaptic connectivity between layer 1 inhibitory interneurons and layer $2 / 3$ pyramidal neurons in the rat neocortex. Cereb. Cortex 21, 1818-1826. doi: 10.1093/cercor/ bhq257

Wu, J. P., and Hablitz, J. J. (2005). Cooperative activation of $\mathrm{D}_{1}$ and $\mathrm{D}_{2}$ dopamine receptors enhances a hyperpolarization-activated inward current in layer I interneurons. J. Neurosci. 25, 6322-6328. doi: 10.1523/JNEUROSCI.140505.2005

Xu, X., Roby, K. D., and Callaway, E. M. (2010). Immunochemical characterization of inhibitory mouse cortical neurons: three chemically distinct classes of inhibitory cells. J. Comp. Neurol. 518, 389-404. doi: 10.1002/cne.22229

Yao, X. H., Wang, M., He, X. N., He, F., Zhang, S. Q., Lu, W., et al. (2016). Electrical coupling regulates layer 1 interneuron microcircuit formation in the neocortex. Nat. Commun. 7:12229. doi: 10.1038/ncomms12229

Yizhar, O., Fenno, L., Prigge, M., Schneider, F., Davidson, T., O’Shea, D., et al. (2011). Neocortical excitation/inhibition balance in information processing and social dysfunction. Nature 477, 171-178. doi: 10.1038/nature 10360

Zhou, F. M., and Hablitz, J. J. (1996a). Layer I neurons of rat neocortex. I. Action potential and repetitive firing properties. J. Neurophysiol. 76, 651-667. doi: 10.1152/jn.1996.76.2.651

Zhou, F. M., and Hablitz, J. J. (1996b). Morphological properties of intracellularly labeled layer I neurons in rat neocortex. J. Comp. Neurol. 376, 198-213. doi: 10.1002/(sici)1096-9861(19961209)376:2<198::aid-cne3>3.0.co;2-Z

Zhu, Y., and Zhu, J. J. (2004). Rapid arrival and integration of ascending sensory information in layer 1 nonpyramidal neurons and tuft dendrites of layer 5 pyramidal neurons of the neocortex. J. Neurosci. 24, 1272-1279. doi: 10.1523/jneurosci.4805-03.2004

Conflict of Interest Statement: The authors declare that the research was conducted in the absence of any commercial or financial relationships that could be construed as a potential conflict of interest.

Copyright (C) 2018 Bohannon and Hablitz. This is an open-access article distributed under the terms of the Creative Commons Attribution License (CC BY). The use, distribution or reproduction in other forums is permitted, provided the original author(s) and the copyright owner are credited and that the original publication in this journal is cited, in accordance with accepted academic practice. No use, distribution or reproduction is permitted which does not comply with these terms. 